\title{
LA IGLESIA EN DEFENSA DE LA ENSEÑANZA RELIGIOSA: LA ASOCIACIÓN CATÓLICA DIOCESANA DE PADRES DE FAMILIA DE VALLADOLID (1930-1937)
}

POR

\author{
ENRIQUE BERZAL DE LA ROSA
}

Universidad de Valladolid

\section{Resumen}

Los «Padres de Familia» eran unas asociaciones de carácter eclesial surgidas a finales del siglo XIX y compuestas por seglares para la defensa de la moralidad y cducación católicas. Su activiđad en defensa de la Iglesia fue destacada durante la Segunda República y la Guerra Civil, especialmente en la lucha contra el laicismo en la enseñanza; además, la jerarquía católica se encargaba de fomentar estas asociaciones en las ciudades españolas.

Nuestro estudio se centra en la historia y realizaciones de la Asociación Católica de Padres de Farnilia de Valladolid durante esos años (1931-1937). Su ingente tarea (creación de escuelas, lucha contra el laicismo en la enseñanza y contra el «cine inmoral», etc) estuvo planteada de forma inteligente y eficaz.

\begin{abstract}
«Los Padres de Familia" were an ecclesial associations created in the end of the XIX century to defend the religious morals and the catholic education. They are composed of secular people, and their activities were very important for the protection of the Spanish Church, specially during The Second Republic and The Civil War (1931-1939). Also, the catholic hierarchy fomented these associations in the spanish cities.

We study the history and activities of this association in Valladolid during those years (creation of catholic schools, campaigns against the republican school and the eimmoral cinema», etc). We realize that it was an intelligent and effective labour in favour of the catholic education.
\end{abstract}


A MODO DE INTRODUCCIÓN. EL ASOCIACIONISMO CATÓLICO Y LOS PADRES DE FAMILIA:

Desde la segunda mitad del siglo XIX (a partir, pues, del Concordato de 1851), y al hilo de lo que acontecía en la socieđad española de aquellos años, comienza a pergeñarse de forma importante en la Iglesia española el modelo asociativo seglar como medio adecuado de actuación en la sociedad'; surgen así asociaciones de seglares de tipo benéfico, social, cultural, político, etc, que, en plena consonancia y sumision a la jerarquía eclesiástica, llevan a cabo una nada desdeñable tarea de defensa y apoyo a la Iglesia. No hay que olvidar que el fin último que persiguen no es otro que la reconquista católica de la sociedad, especialmente en una época en que el avance de las teorías secularizadoras y en no pocas ocasiones antirreligiosas, pugnaban por hacerse con el control de todas las esferas sociales, amenazando y luchando contra el predominio eclesial en las mismas.

De esta manera, a finales de la centuria decimonónica surge en Madrid la Asociación de Padres de Familia contra la Inmoralidad, nacida para luchar en favor de los principios católicos en lo referente a la moral sexual.

Durante la dictadura primorriverista, las Asociaciones de Padres de Familia adquieren una gran relevancia y van surgiendo en las distintas ciudades, pues los metropolitanos las encomiendan un papel protagonista en la lucha contra la inmoralidad pública².

La labor de los Padres de Familia, si bien se circunscribía casi exclusivamente al terreno de la moral sexual, no descuidaba la defensa de la educación y escuelas católicas, especialmente en los años en que ésta se sentía amenazada por la actitud de los gobernantes ${ }^{3}$. Pero, sin ninguna duda, la labor principal en

\footnotetext{
1 Ver a cste respecto ANDRÉS-GALLEGO, J., «La Iglesia», en VVAA, Historia General de España y América, Ed. Rjalp, Madrid, 1982, tomo XVI-1 («Revolución y Restauración (1868-1931)», pp. 677-755; MONTERO, F., El movimiento católico en España, Ed. EUDEMA, Madrid, 1993.

2 MONTERO, F., op. cit., pág. 57; para combatir el juego y la inmoralidad («esas plagas de la sociedad modernaw), se hace una llamada en febrero de 1923 por parte de los prelados a la creación de «juntas, celebración de congresos, asambleas, mítines, valiéndose para ello de seglares de reconocida probidad y virtud, y especialmente de la Asociación de Padres de Familian, CÁRCEL OrTi, V., Actas de las Conferencias de Metropolitanos españoles (1921-1965), Ed. BAC, Madrid, 1994, pp. 160-161; en abril de 1925 los metropolitanos fomentan la creación de estas Asociaciones «en todas las poblaciones en que sea posible», ibid., pág. 208, 220-221; en octubre de 1928 y 1929 se siguc solicitando su labor de represión de la inmoralidad pública, ibid., pp. 254, 262-263.

3 El 31 de enero de 1913 surge el proyecto de Romanones, consistente en la no obligatoriedad de la educación religiosa para los hijos de los padres no católicos; además, en marzo de este mismo año, el director general de Primera Enseñanza, Altamira, llevó al Consejo de Ministros una consulta sobre la supresión del catecismo en las escuelas; al final, se decretó no obligatoria la enseñanza del catecismo a los hijos de padres no católicos; MARTI GILABERT, F., Poltica religiosa de la Restaura-
}

El asociacionismo en la iglesia

Hispania Sacra 50 (1998) 
defensa de la enseñanza católica desplegada por estas Asociaciones se lievará a cabo durante la Segunda República española. Frente al laicismo y secularización de la enseñanza impuesta por los nuevos gobernantes republicanos (con la famosa Ley de Confesiones como su mejor exponente) ${ }^{4}$, la Iglesia reacciona por medio de pastorales conjuntas y de una eficaz organización de seglares católicos (siempre supeditados a la jerarquía) que luchen contra las nuevas y desafiantes realidades ${ }^{5}$. Las Asociaciones Católicas de Padres de Familia, la Federación de Amigos de la Enseñanza, los Estudiantes Católicos, la erección de Mutualidades de Padres de Familia, etc, forman parte de la estrategia eclesial en defensa de la enseñanza religiosa frente a la escuela laica ${ }^{6}$.

Para vertebrar y dar eficacia a toda esa acción, se crea la Confederación de Padres de Familia, con sede en Madrid, entidad coordinadora de la actividad de los Padres de Familia y encargada de supervisar y potenciar la creación y propaganda de las diversas Asociaciones. Como ya expuso en su día J. R. Montero, el origen de la Confederación se encuentra en noviembre de 1931, cuando se celebra la Asamblea Nacional de los Padres de Familia: se acuerda crear una Confederación y luchar contra la escuela laica, la coeducación y en favor del reparto proporcional; una Junta denominadora procede a designar el Consejo Directivo ${ }^{7}$. El presidente de la Confederación era D. José $\mathrm{M}^{\mathrm{a}}$ Mayans de Seguera, conde de Trigona, y el secreario D. José $\mathrm{M}^{\mathrm{a}}$ Torre de Rodas. Du-

ción (1875-193I), Ed. Rialp, Madrid, 1991, pp. 126-130. Frente a esto, la Liga de Padres de Familia de Madrid escribe cartas a diversas ciudades para constituir plataformas en defensa de la enseñanza confesional; ver Archivo de Acción Católica de Valladolid (ACdV), ZURRo LLORENTE, E., Historia de la Asociación Católica Diocesana de Padres de Familia de Valladolid.

4 Entre otras obras, se pueden consultar a este respecto: PÉREZ GALÁ́N, M., La enseñanza en la Segunda República Española, Ed. Cuadernos para el diálogo, Madrid, 1977; MOLERo PINTADO, A., La reforma educativa de la Segunda República Española. Primer bienio, Ed. Santillana, Madrid, 1977; MilláN, F., La revolución laica. De la Institución Libre de Enseñanza a la Escuela de la República, Ed. Fernando Torres, Valencia, 1983; LOZANO, C., La educación republicana, Ed. Universidad de Barcelona, 1980; SAMANIEgo BONEU, M., La politica educativa de la Segunda República, Ed. C.S.I.C., Madrid, 1977.

5 PÉREZ GALÁN, M., op. cit., pp. 71-80, 131-136, 156-179; MOLERO PINTADO, A., op. cit., pp. 70-74, 226-232, 351-370; CAPITÁN DíAZ, A., Historia de la Educación en España, vol. II: «Pedagogía contemporánea», Ed. Dykinson, Madrid, 1994, pp. 537-563.

6 Se puede ver en CÄrCEL OrTí, V., op. cit., pp. 289, 291-292 y 346-348.

7 Ver MONTERO GIBERT, J. R., La CEDA. El Catolicismo social y político en la República, Ed. Revista de Trabajo, Madrid, 1977, vol, II, pp. 522-523. Aunque Pérez Galán sitúa su inicio en 1929 (La Enseñanza en la Segunda República española, Ed. Cuadernos para el diálogo, Madrid, 1977, pp. 285-286), ef programa de la Asamblea de Vitoria confirma los datos de Montero: «Desde que en noviembre del año 1931 se constituyó esta organización, en la Primera Asamblea Confederal celebrada en Madrid (...)», ver ACdV, Asociación Católica de Padres de Familia de Valladolid. Carpeta con documentos referentes a las Asambleas celebradas por la Confederación, «Programa de la III Asamblea de Representantes». 
rante la Segunda República se multiplican las Asambleas de los Padres de Familia por toda España: se trata de actos multitudinarios en defensa de la enseñanza confesional y en favor de una revisión constitucional que mitigue el articulado antirreligioso ${ }^{8}$.

Es en este marco general en el que debemos situar la labor de la Asociación vallisoletana de Padres de Familia en defensa de la enseñanza católica; veremos como, siguiendo los dictados del prelado y de la Confederación madrileña (a veces discrepando de ella), la Asociación vallisoletana actuará de manera eficaz e inteligente en la defensa de las escuelas católicas de Valladolid, dentro del más estricto posibilismo y de la más rigurosa legalidad y confesionalidad.

\section{LOS ORIGENES DE LA ASOCIACION VALLISOLETANA. 1913-1915:}

El 15 de diciembre de 1912 la Liga de Padres de Familia de Madrid publicó una circular con el objetivo de formar Juntas en las localidades para que los padres de familia católicos trabajasen juntos «en defensa de la enseñanza religiosa, amenazada por los proyectos y planes de los sectarios»9. La Junta Central de Madrid remite uno de estos ejemplares a Rafael Alonso Lasheras, «quien a la sazón presidía una entidad católica en Valladolid» ${ }^{10}$.

Hacia 1913 funcionaba en esta ciudad una Junta Diocesana de Enseñanza Católica, que intervino, bajo la direccion del cardenal Cos y Macho, en defensa de la enseñanza católica; esta junta recogía y organizaba las suscripciones del profesorado e intelectuales «para las fracasadas asambleas que en Madrid pensaban realizar con el nombre de Cultura Popular o Asamblea de Enseñan-

8 El punto de partida es la Asamblea de la Confederación celebrada en Madrid durante los días 21-23 de octubre de 1932, en la que se pergeña el reglamento general para la actuación y creación de las Asociaciones; a partir de ahí, las Asambleas se multiplican (las Generales de Vitoria, 23-30 de julio de 1933; Covadonga, 8-15 de julio de 1934; Granada, 9-12 de mayo de 1935. También las Regionales de Avila, 12-13 de octubre de 1935; Palencia, 16-17 de noviembre de 1935; Lcón, 14-15 de diciembre de 1935); ACdV, Asociación Católica de Padres de Familia de Valladolid. Carpeta con documentos referentes a las Asambleas celebradas por la Confederación.

9 La «Ley del Candado de Canalejas»; dice cl autor que así despertaban los católicos de un largo letargo, «dañif̂o y prolongado», ACdV, Zurro Llorente, E., op. cit.

10 ACdV, ZurRo LLORENTE, E, Don Rafael Alonso Lasheras, recuerdos de su actuación en el campo católico y político, Valladolid, 7 de cnero de 1957; se trata de un documento mecanografiado del autor que acompañó a Lasheras en su labor, y más específicamente, en su gestión frente al gobierno de la República a favor de las Ordenes religiosas. Rafael Alonso Lasheras era en 1912 presidente de la Federación de Sindicatos Agrícolas Católicos, creada gracias al impulso del P. Nevares: ver GorRindo, F., La Casa Social Carólica de Valladolid, 1915-1936, Universidad de Valladolid, 1978 ( "Tesina “ mecanograftada), pp. 217-254, y del mismo autor, «La Federación de Sindicatos Agrícolas Católicos de Valladolid», ел Investigaciones históricas (1979).

El asociacionismo en la iglesia

Hispania Sacra 50 (1998) 
za los que por su modo de pensar y por antecedentes de las celebradas en otras naciones eran motivo de justificados recelos para los católicos» ${ }^{11}$. También participó esta junta en la organización del I Congreso Catequístico español, celebrado en Valladolid, los días 26, 27, 28 y 29 de junio de 1913.

Alonso Lasheras trasladó esa circular de la Liga madrileña a la Junta Diocesana de Enseñanza Católica, «en la que encontramos la raíz de la actual Asociación Católica de Padres de Familia»' ${ }^{2}$. El cardenal Cos deseaba que los padres de familia fuesen los que formasen parte de la Junta a crear según las indicaciones de la Liga Madrileña. Por eso, el Abad de Párrocos y secretario de la Junta Diocesana de Enseñanza, Angel Morante, designado ese año, consultó con sus compañeros; éstos le citaron varios nombres de los respectivos feligreses, para procurar que cada parroquia estuviese representada en la formación de dicha Junta. El 27 de junjo de 1913, Rafael Alonso Lasheras pedía a dicho Abad de Párrocos que convocase una junta, pues los señores Masa y Bahía, de Madrid, deseaban hablar y proponer la conveniencia de crear la Junta de Padres de Familia.

Convocada ésta con la venia del Cardenal Cos, se relataron las gestiones llevadas a cabo en Madrid, en distintos Departamentos y ante el rey de España por parte de la Junta Central, en favor de la enseñanza religiosa. Se remitieron comunicados a la prensa católica ${ }^{13}$ «para propaganda entre los padres de familia»14. El periódico católico vallisoletano, Diario Regional, informa que el 11 de mayo de 1914 tiene lugar en la sacristía de la parroquia de Santiago «una junta de padres de familia, que presidió Angel Morante, abad de párrocos, con numerosa asistencia» ${ }^{15}$. Se acuerda de este modo la necesidad de agrupar a los padres de «familia» en defensa de la educación cristiana de sus hijos, «amenazada por tendencias sectarias» ${ }^{16}$, y la conveniencia de asociarse en esta ciudad, siguiendo el ejemplo de otras poblaciones.

\footnotetext{
${ }^{11}$ ACdV, ZURRo, E., Historia..., op. cit., pág.3

12 ACdV, ZURRo, E., D. Rafael Alonso Lasheras..., op. cit.

13 Seguramente en cl Diario Regional.

14 E. Zurro habla así del comunicado denominado «Toque de llamada», publicado por los peri6dicos locales, con el objetivo de propagar lá notica de la creación de esa Junta. Op. cił,. pág 4.

${ }_{15}$ Citado por E. Zurro, Historia,..., op. cit., pág 4, el cual regoge la información del número correspondiente al 12 de mayo de 1914, del Diario Regional. A continuación, cl autor cita -aún de dicho periódico- los nombres de los asistentes: Francisco Borge (párroco de dicha iglesia), Juan Antonio LLorente (diputado provincial), Demetrio Padilla, Valentín Martín, Pedro de Prada, Plácido Rubio, Antonio Ortiz đe Urbina, M. Calvo, Félix Lago, Justo Guzmán, Enrique Ortiz, Francisco Perelétegui, Manuel Herrera, Manuel López, Miguel López Guerra, Eduardo Lázaro, Maruel Vicente, Gcrardo Elias, Donato Villa, Rufino Belloso, Vicente Alonso, y otros.

16 Op. cit., pág 5.
} 
Posteriormente, acordaron que una comisión se dirigiese al Palacio Arzobispal a fin de dar cuenta de lo convenido al Cardenal, poniéndose de inmediato en marcha. Allí el Cardenal animó a los padres de familia a perseverar en esta actuación, alentándoles a no cesar de «reivindicar los fueros que por derecho natural les pertenece, frente a las doctrinas heréticas del liberalismo» ${ }^{17}$. También el periódico El Porvenir ${ }^{18}$, dio a conocer la reunión de esa junta.

Algunas actividades desplegadas por ésta en sus primeros años de existencia, ponen de relieve el carácter de reconquista católica de la sociedad que alienta la actividad de la jerarquía y de los católicos organizados en estas fechas, y en la que una de las bazas de gran peso es la que hace referencia a la defensa de la enseñanza católica ${ }^{i 9}$ :

- Varios padres de familia denuncian al Cardenal Cos el libro de Francisco Santamaría (sic), Etica Social; el Edicto de Condenación y Prohibición aparece en el Boletín del Arzobispado el 14 de noviembre de $1914^{20}$.

- El 23 de diciembre de 1914 se reúnen varios padres de familia en el Círculo de Obreros y acuerdan dirigirse al cardenal para darle las gracias «por la solicitud con que atiende a defender la pureza de la doctrina y por la acogida que dispenso al pliego de denuncia firmado por varios padres de familia que representan a 350 adheridos ${ }^{21}$. Así, el día 24, acudieron al Palacio Arzobispal en compañía también del marqués de la Solana. El cardenal les agradeció su visita, y les dio más consejos acerca de su organización.

- El 26 de mayo se volvieron a reunir los representantes de las parroquias en el mismo local, y se nombraron los representantes que formarian la Junta Directiva; respecto al reglamento, se tendría como referencia el de Madrid. El 26 de abril de 1915, tiene lugar su primera reunión en el Palacio Arzobispal,

17 lbíd. El mismo cardenal se lamentaba de que se pretendiese que la enseñanza sólo fuese llevado a cabo por el Estado, y no se permiticse a la Iglesia ni a los padres de famila realizar esta actividad.

${ }^{18}$ Cuyo director era Juan Antonio LLorente García, diputado católico y más tarde conservador de E. Dato.

${ }^{19}$ Que arranca ya de finales del XIX, y se hạce más explícita en los diferentes Congresos Católi$\cos (1889-1902)$.

${ }^{20}$ Para ello, el Cardenal Cos y Macho nombró una comisión de doctores que examinase dicho libro; «después de un maduro examen, [la Comisión] nos ha informado, por unanimidad, que en dicho libro se contienen proposiciones herêticas e impías, doctrinas inmorales y escandalosas, y por tanto, procede que recaiga sobre él la condenación eclesiástica (...) prohibimos a todos los fieles de esta dícessis la lectura y retención de dicho libro, así como a los libreros e impresores católicos su venta y reimpresión, BAV, noviembre de 1914.

${ }_{21}$ ACdV, ZURRO, E., Historia de la Asociación Católica Diocesana de Padres de Familia de Valladolid, pág. 6.

Ej asociacionismo en la iglesia

Hispania Sacra 50 (1998) 
bajo la presidencia del cardenal de Valladolid ${ }^{22}$. En ella proponen a la Junta de Padres de Familia contra el Laicismo en la Enseñanza el nombramiento de una Junta Local «que coadyuve a los trabajos de la Central y solicite su ayuda a lo que interese a la enseñanza que se da en esta ciudad, desde el punto de vista católico» ${ }^{23}$. De esta manera, se propone la Junta, presidida por Juan A. Llorente y aprobada por el Cardenal Arzobispo, Sr. Cos y Macho ${ }^{24}$. Se acordó que no se constituyese como entidad independiente, sino que formase parte de la ya existente con carácter nacional.

22 Se reánen: el Padre Paz S.J., LLorente, L. Herrero, Prada, Padilla, O. de Urbino, Morante, Lago, Delgado; Calvo, F. Zamora.

23 ACdV, ZURRo, E, Historia..., op. cit., pág 7. Los Estatutos de la Asociación Nacional de Padres y Jefes de Familia contra el Laicismo en la Enseñanza, especificaba a la perfección sus fines: «(...) la defensa, dentro del orden legal, de los derechos que la ley divina, la ley natural, la constitución del Estado y demás disposiciones vigentes les conceden para la instrucción y educación de sus hijos y pupilos en materia religjosa» (art, 1). Exponía además que «La Asociación tendrá su domicilio en Madrid, en la calle del Príncipe, $\mathrm{n}^{\circ} 7$ principal» (art. 2) y que "(...) estará regida por una Junta Directiva Nacional, residente en Madrid, formada por un presidente, un secretario, un tesorero, y un número de vocales que no scrá inferior a seis» (art. 3). Estatutos firmados en Valladolid, el 27 de abril de 1915.

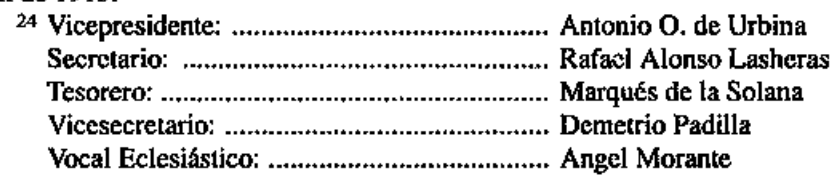

A continuación, se nombran los distintos voacales por parroquias:

\begin{tabular}{|c|}
\hline 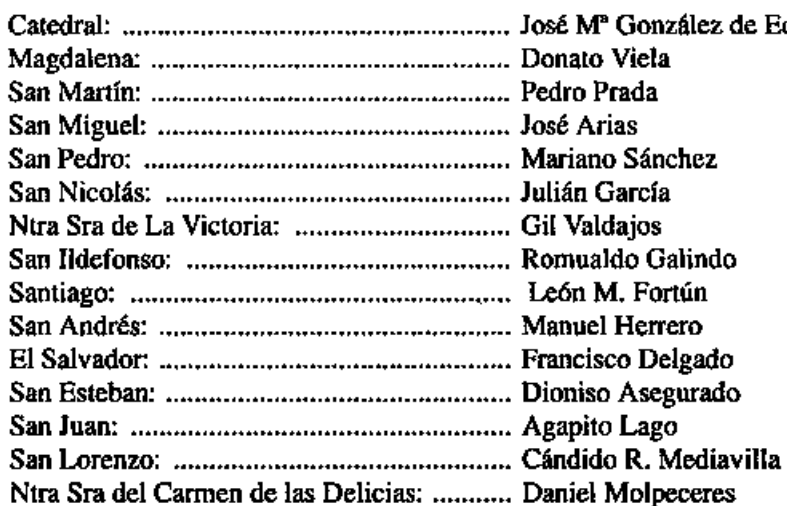 \\
\hline
\end{tabular}

Ntra Sra del Carmen de las Delicias: ............ Daniel Molpeceres

No aparece en los documentos el nombre del Secretario, pero suponemos que será Alonso Lasheras, ya que en la reunión del 6 de mayo de 1915, en la que se presenta formalmente la Junta Católica de Padres de Familia de Valladolid y se ratifica por tanto la composición que vemos en esta reunión de abril de 1915, aparece como Secretario. 
Ese mismo día se reúne la Junta Directiva de Padres y Jefes de Familia, y el secretario informa la aprobación por parte de la Junta de Madrid de la creación de la vallisoletana, según el artículo $7^{\circ}$ del Reglamento ${ }^{25}$, y conforme a lo sostenido en la reunión anterior. De esta manera, se acuerda presentar al Gobernador los Reglamentos para su inscripción.

La Junta Católica de Padres de Familia de Valladolid se constituye formalmente a partir de la reunión del 6 de mayo de 1915, con la composición vista anteriormente.

\section{LA "RESTAURACION" (1930):}

La Asociación no vuelve a reunirse hasta el 20 de enero de 1930; E. Zurro habla, pues, de «vida latente o crisis de la Asociación» 26.

La nueva constitución y la potenciación de la misma, como baluarte para la defensa de la enseñanza católica, son obra del arzobispo Gandásegui: «Gracias a él pudo reorganizarse aquella antigua Asociación de Padres y Jefes de Familia contra el laicismo en la Enseñanza, que yacía inerte en un Libro de Actas encerrado en un cajón. Gracias a él pudo constituirse sobre aquella base nuestra actual Asociación Católica, de la que jamás consintió en separarse, por lo que la estableció generosmente en su propio palacio; es decir, que gracias a él también, tenemos oficinas cómodas y gratuitas, con toda la autoridad y prestigio que da el estar domiciliado en el Palacio Arzobispal»27.

\subsection{El pesimismo de los primeros momentos (1930-1933):}

\section{a) La Asociación se pone en marcha:}

La Asociación se pone en marcha a partir de esta fecha ${ }^{28}$, siendo sus primeros dos años desde su reinstalación un período de lenta iniciación, con escasas

\footnotetext{
25 «La Asociación creará juntas locales en las poblaciones que se estimen necesarias, que entrarán en relación con la junta nacional de Madrid y tendrán una composición semejante», ACdV, Estatutos de La Asociación Nacional de Padres y Jefes de Familia contra el Laicismo en la Enseñanza, Valladolid, 27 de abril de 1915.

26 ACdV, E. ZURRO, Historia de la Asociación Catolica Diocesana de Padres de Familia de Valladolid, pág. 10.

27 ACdV, Asociación Catolica de Padres de Familia de Valladolid. Memoria correspondiente al año 1937, pág. 1.

${ }^{28}$ Comienza de Presidente José Valverde, Vicepresidente Francisco Presa, Secretario Rafael Vidal y Tesorero Luis Silió, en ACdV, Libro de Actas de la Asociación Católica de Padres de Familia de Valladolid, pág. 8.

El asociacionismo en la iglesia Hispania Sacra 50 (1998)
} 
actividades ${ }^{29}$. Es ahora cuando se produce el cambio de presidente, pasando a ser desempeñado dicho cargo por Francisco Presa.

En febrero de 1932 el delegado de la Confederación Nacional de Padres de Familia, José María Torre de Rodas, acude a la reunión de la Asociación vallisoletana del día 6, para expresar el deseo de «dar nuevo impulso a todas las Asociaciones procurando aumentar el número de socios, haciendo para ello una intensa propaganda por medio de conferencias, para lo cual propuso la conveniencia de nombrar un comité en el cual delegara todas sus atribuciones la Junta Directiva» ${ }^{30}$. Todos los asistentes aprobaron la propuesta, con lo que dicho Comité quedó formado ${ }^{31}$.

El once de junio de 1932 Francisco Presa acuerda disolver la actual Junta y nombrar una nueva. El arzobispo Gandásegui nombra Consiliario a Alberto Palomino, párroco de San Pedro, y una vez restablecido de su enfermedad, a finales de junio de 1932, aprueba la nueva composición de la Junta Directiva ${ }^{32}$. Destaca el carácter fuertemente confesional de la Asociación, manifestado en la total y completa sumisión al prelado, aspecto típicamente característico de la Acción Católica ${ }^{33}$. En la reunión del 15 de junio se llega a tres acuerdos importantes: dar cumplimiento al artículo 10 de la Ley de Asociaciones, nombrar una Comisión organizadora formada por el Presidente, Secretario y Vicesecretario,

29 De 1930 a principios de 1932 sólo destaca el nombramiento de representantes para la Junta del Patronato Universitario: primeramente se elije a los Sres Luis Silió y Rafacl Serrano (21 de enero de 1930); luego se desestima la elección de Luis Silió al no tener hijos csłudiando en la Universidad, siendo sustituído por Amando Valentín (31 de cnero de 1930). Ver ACdV, Libro de Actas..., op. cit., pp. 8-9.

30 lbid., pág. 9.

31 Estaba formado por: Justo Medrano, Miguel Prado, Julio G. De la Puente, Arias Bulnes, Danie! Alvarez, Germán Adanez y Eugenio Lobón, ibid., pág. 10.

32 Presidente: ................................... Fernando Carro Izquierdo Vicepresjdentc: ............................ Germán Adanez Honajuelo

Secretario: ................................... Pedro Plaza Valverde

Vicesecretario: ............................. Eugenio Lobón Belmonte

Tesorero: ........................................ Julián Velasco Mucientes

Vicetesorero: .................................. Arias Bulnes Trespalacios

Vocales Asesores: ....................... Nicolas sánches de Otto y Daniel Alvarez

Consiliario: ...................................... Alberto Palomino

Vocales: .......................................... Justo Medrano, Julio G. de la Puente, Vicente Sánchez de León, José Martínez Fortún, Lucio Gabriel y Matías Masa Cabezón.

en ACdV, Libro de Actas..., op. cit., pág. 11.

${ }^{33}$ Así, la reunión del 15 de junio de 1932 comienza invocando -como en todas las reuniones- al Espíritu Santo, y con el acuerdo de enviar a Gandásegui «nurestra inquebrantable adhesión, bumilde sumisión y filial afecton, con motivo de la enfermedad del arzobispo, agravada en estas fechas; ver ACdV, Libro de Actas..., op. cit., pág. 13. 
Tesorero y Vicetesorero, y establecer reuniones entre los señores de la Junta cada ocho o diez días, con el fin de «cambiar impresiones» ${ }^{34}$.

El primer punto se pone enseguida en marcha, pues una semana después el Presidente informa del envío, el día 16, al Gobernador, de un oficio y un certificado expedido por el Secretario, del acta de la Asamblea, en la que constan las personas que ejercen cargos de la directiva, según dicho artículo $10^{35}$. El siguiente paso es la creación de Comisiones, como medio imprescindible para una eficaz actuación; se crean por lo tanto, la Comisión de Reglamentos, formada por los Sres. Adanez y Otto ${ }^{36}$, la Comisión Financiera, por los Sres. Velasco, Sánchez đe León y Bulnes, encargada de la confección de presupuestos y la formación del Grupo «Socios protectores»; y la Comisión de organización de propaganda y Censo, que la integran los demás miembros de la Junta. «Estas Comisiones trabajarán independientemente» ${ }^{37}$.

\section{b) Un ambiente poco optimista:}

A mediados de 1932, la actividad de la Asociación aún precisa de una mayor solidez, esto es, un mayor número de afiliados; así, en la reunión del 12 de julio, se expone la necesidad de debatir «el modo de que rápidamente se consiga el número de asociados indispensables para que la Asociación pueda cumplir su fin». Y es que, pese al avance experimentado en el número de socios, éste aún es escaso ${ }^{38}$.

Se trata de una situación difícil la de los primeros momentos, pues sólo basta leer las impresiones que el presidente, F. Carro, envía a la Confederación madrileña: «Estaba y estoy preocupado (mi pesimismo, por supuesto), por el estado de la Asociación en estos momentos y mis primeros pensamientos y trabajos los dirigi (y aún estoy en ello) a legalizar la situación y a preparar ulteriores trabajos que, aunque necesarios, me parecen menos urgentes». Рara organizar el reglamento de la Asociación, el presidente pide a $\mathrm{M}$. Torre de Rodas el de la Confederación, otro de la Federación de la Diócesis de Madrid y otro de la Asociación local ${ }^{39}$. Además, parece que desde el punto de vista

\footnotetext{
${ }^{34}$ Ibid.

35 ACdV, Libro de Actas..., op. cit., pág. 14.

${ }^{36}$ Que contará con la ayuda del Sr. Escudero, entusiasta de nuestra Asociación», ibid., pág. 15.

32 lbid.

38 1930: 126 socios sin cuota

1931: 135 con «cuotas raras»

1932: 243 con cuota «infima (de pescta anual a 5 pesetas mensuales; de ésta hay sólo una».

${ }^{39} \mathrm{ACdV}$, Asociación Católica de Padres de Familia. Correspondencia recibida y contestada de la Confederación en el año de 1932, «Carta de F. Carro a la Confederación Catolica de Padres de Familia, Valladolid, 18 de junio de 1932».
} 
económico la marcha de la Asociación vallisoletana tampoco es muy positiva: «la situación económica no es buena aunque no creo muy dificil arreglarla. Hay un déficit de mil pesetas (...) debido únicamente a la Asamblea celebrada y más especialmente al mitin del Teatro Calderón» ${ }^{40}$. Pero dicho déficit hace que tenga que retrasarse dos meses la cuota de 75 pesetas que la Asociación vallisoletana debe pagar a la Confederación ${ }^{41}$. (Los aspectos económicos, no obstante, serán expuestos más adelante con una mayor sistematización).

También en estos primeros años hay una gran preocupación por la propaganda ${ }^{42}$ y por el sólido asentamiento de la Asociación en toda la Diócesis: para ello se contacta con los párrocos ${ }^{43} \mathrm{y}$ con los arciprestes ${ }^{44}$. Se acuerda también el nombramiento de las personas más aptas para representar a la Asociación en las distintas parroquias ${ }^{45}$ y se presta gran atención a la marcha de los trabajos encomendados a los Delegados en los diferentes Colegios ${ }^{46}$.

\section{c) El modelo madrileño:}

La organización de la Asociación vallisoletana inicia su andadura gracias a la colaboración de la Confederación madrileña y más concretamente del secretario, Torre de Rodas. Se toma como modelo los informes enviados por el mismo ${ }^{47}$ :

- En la organización de Secciones Parroquiales y en las Secciones en los Colegios: «Las Secciones en parroquias y colegios han de ser como las "células " de nuestra obra y su organización debe tener por base la norma contenida en los artículos 17 y 18 del Modelo de Reglamento de Asociación» ${ }^{48}$.

- En la Federación y Asociaciones en los Pueblos: es necesario mantenerse fieles a la Jerarquía eclesiástica. Es preciso seguir la organización eclesiástica, pero si existe algún tipo de dificultades se debe obrar con cierta flexibili-

40 ACdV, Ibid., «Carta de F. Carro a la Confederación Calólica de Padres de Familia, Valladolid, 27 de junio de 1932".

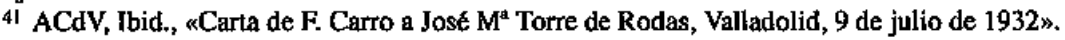

42 ACdV, Libro de Actas, ,..., op. cit., pp. 18-19.

43 Reunión del 26 de julio de 1932, en ibid., pág. 20.

44 Reunión del 4 de octubre de 1932, ibid., pág. 21.

45 Reunión del 11 de octubre de 1932, en ibid., pág. 23. Las secciones parroquiales aún se siguen ultimando en la reunión del dos de noviembre de ese mismo año (pág. 25). El 26 de noviembre ya se han constituido las secciones partoquiales de Santiago, San Andrés, El Salvador y San Pedro (pág. 27). El 7 de diciembre se nombran comisiones upara gestionar la creación de aquellas [Juntas Parroquiales] donde no las hubieren (pág. 28).

46 Por medio de una «reunión a fin de cambiar impresiones», Ibid.

47 ACdV, Asociación Católica de Padres de Familia. Correspondencia recibida y contestada de la Con. federación en el año de 1932, «Carta de J. M" Tarre de Rodas a F. Carno, Madrid, 19 de agosto de 1932».

48 Ibid. 
dad, «sobre todo en un principio». Si hay algún inconveniente en Valladolid para constituir las Asociaciones locales a base de Arciprestazgos, se puede emplear una fórmula más apta «para el mejor desenvolvimiento de la obra». La organización en los pueblos debe tener el carácter de "Asociación», y no de «Sección». Todas las Asociaciones de los Pueblos, más la de la capital, formarán la «Federación», por lo que ésta «no es sino el conjunto de Asociaciones». Habrá una Junta Directiva, y resulta conveniente que esté presidida por el mismo presidente de la Asociación de la capital, «y constituida poco más o menos con los mismos componentes».

- Cuotas: al haber fracasado el sistema de cuota confederal anual por socio en el ámbito agrario, se impone el sistema basado en «la fijación de un cupo convenido con cada organización. Es decir, cada Asociación local debe fijar el cupo mensual con que puede contribuir a formar la "hacienda " de la Federación. A su vez, la Federación recaudará esas cuotas y determinará con la Confederación la cuota confederal».

\subsection{El progresivo afianzamiento desde fines de 1932:}

En la teunión del dos de noviembre de 1932 se acuerda pedir al arzobispo, por parte del Presidente y del Consiliario, la fundación de la Junta Diocesana de Escuelas y Catequesis ${ }^{49}$; Gandásegui accede gustoso a este proyecto, y encarga a la Asociación la redacción de las bases ${ }^{50}$. Preparadas por F. Carro y el Consiliario el 16 de noviembre, son aprobadas, por lo que la Junta Diocesana queda constituida el 7 de diciembre de $1932^{51}$. Ni que decir tiene que el mo-

49 Un día después, del 3 al 6 de noviembre, se reunirían los Metropolitanos y acordarían aconsejar la labor de los Padres de Familia en pro de la cnseñanza católica, en íntima subordinación a los respectivos prelados; ver Cárcel Ortí, V., Actas de los Metropolitanos Españoles (1921-1965), Ed. BAC, Madrid, 1994, pág. 289.

50 ACdV, Libro de Actas..., op. cit., pp. 25-26. En otro lugar se dice; «él constituyó (...) la Junta Diocesana de Enseñanza, gracias a la cual pudicron recibir educación católica infinidad de nix̌os», en ACdV, Asociación Católica de Padres de Familia de Valladolid Memoria Correspondiente al año I937, pág. 1.

s1 Ibid., pp. 26-28. La composición es la siguiente:

Presidente: ............................... Germán González, representante del prelado
Consiliario: ............................ Alberto Palomino
Secretario: .............................. Juan Lanin
Vicesecretario: ......................... Eugenio Labrador
Tesorero: ................................ Francisco Presa
Vicetesorero: ............................. Modesto Mateo
Vocales: .................................. Pascual Pinilla, Fernando Carro, R. Llorente, Pedro de la
Cuesta y A. Valentín

En ACV, Libro copiador o libro de registro (1902-1940), «5 de dicicmbre de 1932», pág. 168.

El asociacionismo en la iglesia

Hispania Sacra 50 (1998) 
delo en que se basa es el madrileño, siguiendo las instrucciones de Torre de Rodas: «Una vez puesta en marcha la organización del Comité Diocesano de Escuelas, debe comenzar a actuar por medio de sus delegaciones, estudiando la situación de la enseñanza católica en la capital y en los pueblos en donde vaya extendiendo su actividad. Con el dinero recaudado en las colectas, se atenderá ante todo a robustecer aquellas escuelas católicas que ya estén funcionando y a crear otras escuelas nuevas en los barrios en donde sean más necesarias» ${ }^{52}$.

También a principios de noviembre comienza a discutirse la forma de lievar a efecto un Patronato de Colegios de Religiosos ${ }^{53}$.

Parece ser que en estos momentos la situación de la Asociación es mejor, y los aires que corren entre sus miembros son bastante optimistas ${ }^{54}$.

\section{a) Las discrepancias entre la Asociación vallisoletana y la madrileña:}

A principios de diciembre de 1932, ante el Proyecto de Ley de Confesiones y Congregaciones la Confederación madrileña acuerda llevar a cabo campañas de protesta en contra de la misma y en favor de la enseñanza religiosa. La Asociación vallisoletana, en nombre de su presidente y siguiendo instrucciones del arzobispo, muestra su disconformidad y su oposición a la iniciativa madrileña, fundamentándola en tres razones ${ }^{55}$ :

1- Porque lo acordado en la Asamblea Confederal de Madrid (21 a 23 de octubre de 1932) no permitía este tipo de acciones cuando fuesen contraproducentes y «ociosas», y esta campaña lo es.

2- Por que la fuerza de las Asociaciones de Padres de Familia no es tan clara como para poder llevar adelante este proyecto: en la mayoría de los pueblos y ciudades aún no están consolidadas, muchos católicos no pertencen a las Asociaciones, $y$ «no pocos de los afiliados habrían de negarse a consignar su protesta (por los cargos que desempeñan)»; en definitiva, «sería un verdadero fracaso, toda vez que se harían públicas las débiles fuerzas de que disponemos

$52 \mathrm{ACdV}$, Asociación Católica de Padres de Familia. Correspondencia recibida y contestada de la Confederación en el año de 1932, «Carta de J. M³ Torre de Rodas a F. Carro, Madrid, 10 de noviembre de 1932\%.

53 lbid., pág. 25.

54 «No sabe Vd. cuánto me agradan las noticias que me dá Vd. respecto a ese entusiasmo cada día más creciente que advierte entre sus compañeros de directiva y cn la forma que desarrollan la labor que están haciendo para constituir secciones parroquiales», en ACdV, Ibid., «Carta de J. $\mathbf{M}^{\mathrm{s}}$ Torre de Rodas a F. Carro, Madrid, 25 de novienbre de 1932».

55 Ver ACdV, Asociación Católica de Padres de Familia. Correspondencia recibida y contestada de la Confederación en el año de 1932, "Carta de F. Carro a J. Mª Torre de Rodas, Valladolid, 6 de diciembre de 1932n. Ver también ACdV, Libro de Actas..., op. cit., pp. 27-28. 
actualmente (...) fracaso que serviría de pretexto para agravar el proyecto presentado y de estímulo para su aprobación”.

3- Además, el arzobispo Gandásegui así lo hizo ver en el momento de la creación de la Junta Diocesana de Enseñanza: «nos dijo que nuestra labor debía ser sólo "positiva ", de sostenimiento, apoyo y creación de centros católicos docentes; nada nos indicó de protestas, antes de sus palabras se deducía claramente lo contrario. Y es natural: si urge salvar la enseñanza católica, todas nuestras energías, tiempo y dinero deben emplearse en ello y no malgastarlos en una labor negativa de protesta, cuyos resultados serían, por lo menos, muy dudosos.

¿Y cómo voy a proponer yo Io contrario que mi Prelado?»

En definitiva, se trata de una actitud prudente, comtemporizadora, alentada desde las instancias jerárquicas y fielmente apoyada por F. Carro, en contraposición con la jerarquía eclesiástica madrileña y la Confederación de Padres de Familia $^{56}$.

La contestación del secretario de la Confederación madrileña es amable y acata lo acordado por Valladolid, haciendo hincapié en el necesario seguimiento de lo dispuesto por el prelado. Pero, con todo, sigue viendo necesaria la protesta, pues «sería un hecho lamentable que la Ley de Congregaciones pasara sin oirse la voz de los católicos ${ }^{57}$.

Cuando se despliega la campaña (1933), la Asociación Vallisoletana sólo remite un escrito de protesta al Presidente del Consejo de Ministros. Torre de Rodas lo agradece, y aunque reconoce que, como apuntó Gandásegui, de nada servirá, sigue apoyando la protesta para que se oiga la voz de los católicos ${ }^{58}$.

b) La voluntad de avanzar:

El 23 de enero de 1933 se lleva a cabo la Junta General de la Asociación en el Salón de Actos de la Casa Social Católica, cuyos preparativos comienzan el 21 de diciembre del año anterior. Además de felicitar a la Junta Directiva por su actuación, salieron a relucir tres problemas importantes:

\footnotetext{
S6 «No dudo que ustedes hayan pedido y obtenido la aprobación por la autoridad competente de

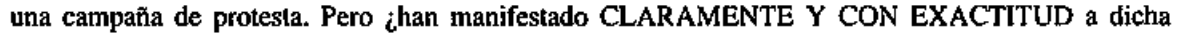
autoridad las fuerzas de que disponemos para realizar dicha campan̄a? ¿Esa superioridad competente tiene autoridad en todas las diócesis españolas?», ibid.

57 ACdV, Asociación Católica de Padres de Familia. Correspondencia recibida y contestada de la Confederación en el año de 1932, «Carta de J. M $\mathrm{M}^{\mathfrak{a}}$ Torre de Rodas a F. Carro, Madrid, 9 de diciembre de $1932 m$.

58 ACdV, jbid., 1933, "Carta de J. Ma Torre de Rodas a F. Carro, Madrid, 10 de marzo de 1933». 
1) El bajo número de afiliados (368), considerado por varios miembros como un número «demasiado pequeño», para una ciudad como Valladolid. Para aumentarlo, se acuerda llevar a cabo una intensa propaganda, pues se entiende que «la influencia y eficacia de nuestra Asociación está en proporción directa con el número de asociados» ${ }^{59}$.

2) Persisten dudas acerca de la organización interna de la Asociación.

3) Se acuerda emplear «todos los medios lícitos» para procurar la enseñanza católica en la Universidad ${ }^{60}$.

A fines de enero de 1934, se efectúa el cambio de presidente, pasando a ser desempeñado el cargo por Juan G. Regueral. Torre de Rodas exhorta al nuevo presidente a trabajar en pos de la educación católica, especialmente de la juventud universitaria, a la que considera en crisis de valores ${ }^{61}$. Juan G. Regueral se propone actuar eficazmente en esta dirección, para lo cual pide consejo y ayuda a Madrid (folletos y disposiciones). La colaboración entre la Confederación y la Asociación vallisoletana es intensa ${ }^{62}$.

En diciembre de este año, el número de asociados ha ascendido ya a $803^{63}$. $\mathrm{Y}$ en cuanto al balance económico, tras la visión pesimista de los primeros momentos, las cuentas arrojan a partir de 1933 saldos favorables ${ }^{64}$.

Para el curso 1934-1935, poseemos el «Programa a realizar», el cual es bastante completo y ambicioso ${ }^{65}$ : Perfecta organización de las Secciones Parroquiales y extensión de la organización a todos los pueblos de la Diócesis; Fomento de la Misa de Comunión mensual y de los Ejercicios Espirituales especiales para hombres; Potenciar los Círculos de Estudios; cursos de religión y moral para jóvenes de ambos sexos; propaganda «Pro Libertad de enseñanza», por el reparto proporcional escolar y Reforma de la $2^{\mathrm{a}}$ enseñanza, y en contra del sectarismo en los Centros docentes, la Coeducación y la pública inmoralidad; llevar a cabo un Censo escolar (estadística de Escuelas, de Maestros, de Consejos escolares, de matrícula escolar); vigilar la enseñanza que se da en los centros oficiales, procurat evitar la coeducación, «hacer menos duro

59 ACdV, Libro de Actas..., op. cit., pág. 31

60 Ibid.

61 ACdV, Asociación Católica de Padres de Familia. Correspondencia recibida y contestada de la Confederación en el año de 1934, «Carta de J. Ma Torre de Rodas a Juan G. Regueral, Madrid, 8 de febrero de 1934n.

${ }^{62}$ ACdV, ibid., «Carta de Juan G. Regueral a J. M ${ }^{a}$ Torre de Rodas, Valladolid, 15 de febrero de 1934»; «Carta de J. M* Torre de Rodas a Juan G. Regueral, Madrid, 2 de marzo de 1934».

63 Ver Anexo I.

64 Ver Anexo II.

65 Ver ACdV, Asociación Catolica de Padres de Familia de Valladolid. Circular núm. 3, 7 enero 1935, pág. 3. 
y peligroso el actual plan del bachillerato», fomentar la enseñanza católica, favoreciendo de un modo especial las nuevas escuelas católicas de San Andrés y Delicias; Cooperar con la Junta diocesana de Acción Católica al fomento de la Prensa católica y de la moralidad en los espectáculos, y a la lucha contra la blasfemia, inmoralidad pública, prensa pornográfica, etc.

No tenemos noticia de la próxima Junta General hasta la anunciada para el 18 de enero de 1935. En ella se constata dos hechos: la organización ha crecido bastante, por lo que sus obras han ganado en envergadura, y como resultado de esto, se precisa una mayor organización y cooperación entre los asociados. Se vuelve a insistir en la necesidad de organizar eficazmente las secciones parroquiales. El fin último y mayor que inspira la actividad de la Asociación es clara: «la reconquista de la enseñanza», la cual «no puede realizarse en un día ni sin esfuerzos por parte de quienes tienen el deber gravísimo e insubrogable de educar cristianamente a sus hijos (...) viviendo en un régimen democrático no es posible prescindir de la masa. Hay que conquistarla en la capital y en los pueblos con una intensa y perseverante propaganda. ¡Cuánta mies y qué pocos operarios para recogerla!».

Hacia 1935 flota la idea de llevar a cabo en Valladolid una Asamblea General; pero según el presidente, Juan G. Regueral, se trata de un proyecto casi imposible, «pues este Seminario dista mucho de ser como el de Vitoria ${ }^{66}$ y no creo encontremos local en condiciones, no obstante nuestro buen deseo» ${ }^{67}$; pese a esto, la idea que acaricia el presidente es la de llevar a cabo una Asamblea Regional en Valladolid, pues «aunque haya de tardar algún tiempo en conseguirla, espero llegaremos a realizarla ${ }^{68}$. Se proyecta para noviembre de 1935 y para potenciarla, se piensa en la venida al Teatro Calderón de Torre de Rodas «y una o 2 personas más (...) como medio de propaganda para despertar entusiamos algo dormidos y como medio de llegar a figurar más adelante una Asamblea Regional» ${ }^{69}$. La respuesta de Madrid es positiva ${ }^{70}$.

Hacia octubre-noviembre de 1935, se van celebrando a instancias de Madrid pequeñas Asambleas en diversas ciudades como parte de una campaña de

${ }^{66}$ Aludiendo a la Asamblea General de Vitoria.

${ }^{67}$ ACdV, Confederación Calblica de Padres de Familia. Claudio Coello, 32 (Madrid). Correspondencia en el año de 1935, «Carta đe Juan G. Regueral a José $M^{2}$ Torre de Rodas, Valladolid, 10 de junio de 1935m.

68 Ibid.

69 ACdV, Confederación Católica de Padres de Familia. Claudio Coello, 32 (Madrid). Correspondencia en el año de 1935, «Carta de Juan G. Regueral a José $\mathbf{M}^{\mathrm{a}}$ Torre de Rodas, Valladolid, 18 de junio de 1935\%.

70 «Ya saben que me tiene a su disposición para cualquier acto que organicen é iremos desde aquí los propagandistas que sean necesarios», ibid., «Carta de José $\mathbf{M}^{\mathbf{2}}$ Torre de Rodas a Juan G. Regueral, Madrid, 18 de junio de 1935».

El asociacionismo en la iglesia

Hispania Sacra 50 (1998) 
reforma de la Constitución; la noticia llega a Valladolid, pero en diciembre, Juan G. Regueral encuentra aún demasiado precipitada una Asamblea, aunque afirma estar creando «atmósfera» para cuando llegue el momento ${ }^{71}$.

2.3. El Círculo de Estudios y sus dificultades. La Academia de adultos de Las Delicias:

1) Desde finales de 1934 la Asociación Católica de Padres de Familia poseerá su propio Círculo de Estudios como medio privilegiado de formación ${ }^{72}$; la idea surge tras la Asamblea de Vitoria de 1933, en la que se acordó la creación de los mismos, como medio privilegiado para la formación intelectual de los miembros. Para ello, la Junta Directiva nombró una Comisión encargada de la erección del Círculo en Valladolid. También la insistencia de la Confederación madrileña es un aliciente $o$, mejor dicho, casi una obligación ${ }^{73}$. Las materias que se imparten en el mismo se basan en dos encíclicas pontificias: «Divini illius» sobre la educación cristiana de la juventud, y «Casta connubii», acerca del matrimonio cristiano. «La labor de la Comisión en este punto había de limitarse a estudiar detenidamente estas Encíclicas y confeccionar unos Esquemas en que se anotaran "todas " las enseñanzas alli contenidas, ordenándolas cuidadosamente, para facilitar su estudio a los circulistas» 74 . El resultado fue excepcional: los Esquemas se elaboraron, se enviaron a la Confederación para su revisión, con el meritorio hecho de que ésta los imprimió para dirigirlos a las demás Asociaciones de España.

Pero si los aspectos formales parecen marchar positivamente, el número de asistentes no es tan alagüeño; las quejas comienzan nada más inaugurarse el Círculo: «no hemos logrado hasta ahora muestras sensibles del resultado práctico que deseamos, sin tener aún esperanza cierta de que pueda empezar el curso para $1^{\circ}$ de año como deseamos» ${ }^{75}$. En 1935, se dice: «No son pocos los asíduos concurrentes a estas sesiones, pero la Junta desearía que su número aumentara, que, a ser posible, ningán asociado dejara de asistir a ellas, a fin de

7 ACdV, ibid., «Carta de Juan G. Regueral a José Ma Torre de Rodas, Valladolid, 5 de diciembre de 1935\%.

72 Ver ACdV, Asociación Católica de Padres de Familia de Valladolid. Circular núm. $1,1^{\circ}$ Julio 1934, pág. 2.

${ }^{73} \mathrm{ACdV}$, Asociación Católica de Padres de Familia. Correspondencia recibida y contestada de la Confederación en el año de 1934, «Carta de José M Torre đe Rodas a Juan G. Regueral, Madrid, 23 de marzo de 1934».

74 Ibid.

${ }^{75}$ ACdV, ibid., «Carta de Juan G. Regueral a José M² Torre đe Rodas, Valladolid, 14 de dicienbre de 1934». 
proveerse o de afilar las armas con que de continuo hay que luchar en esta modema cruzada impuesta por las necesidades de estos tiempos (...) $»^{76}$. Para el curso 1935-1936, se anuncian unos cursos «interesantísimos»77. Los fines pretendidos con ellos son: «que sirvan de guía, norma, acuerdo, evitación de discusiones inútiles y suscitación de algunas dudas en algunos puntos concretos», así como organizar eficazmente la acción en los pueblos ${ }^{78}$. Pero la ambición era mayor y contenía claros tintes políticos: con ocasión de la campaña de reforma de la Constitución, se pretende «contribuir a la formación de un estado de conciencia y al desarrollo de un movimiento de opinión sobre las reivindicaciones de los católicos en relación con la Religión e Iglesia, la Familia y la Enseñanza» ${ }^{79}$. La segunda etapa del Círculo de Estudios está dedicado a un Cursillo breve sobre Acción Católica, y la causa no es otra que el haber encomendado a la Asociación vallisoletana la constitución de la rama de Hombres de Acción Católica ${ }^{80}$.

${ }^{76}$ ACdV, Asociación Católica de Padres de Familia de Valladolid. Circular núm. 3, 7 enero 1935, pp. 3-4.

${ }^{7}$ Son los únicos que encontramos con más detalle. La primera etapa se compone de:

ESTUDIOS PRELIMINARES

- Lección I: EL INDIVIDUO

- Lección II: LA FAMILIA

- Lección III: LA SOCIEDAD Y LA AUTORIDAD CIVIL

- Lección IV: LA IGLESIA

- Lección V: EL INDIVIDUO Y LA IGLESIA

- Lección VI: EL INDIVIDUO, LA FAMILIA Y EL ESTADO

- Lección VII: RELACIONES DE LA IGLESIA Y EL ESTADO

LA CONSTITUCION ESPAÑOLA DE 1931

- Lección VIII: EL PROYECTO DE CONSTITUCION Y EL EPISCOPADO ESPAN̄OL

- Lecciones IX y X: LA CONSTITUCION Y EL EPISCOPADO ESPAÑOL

- Lecciones XI y XII: LA LEY DE CONFESIONES Y CONGREGACIONES RELIGIOSAS Y EL EPISCOPADO ESPAÑOL

- Lección XIII: LA LEY DE CONGREGACIONES Y S.S. PIO XI

- Lección XIV: LOS PADRES DE FAMILIA Y LA CONSTITUCION

En ACdV, Asociación Católica de Padres de Familia de Valladolid. Circular núm. 7, 7 enero 1936, pág. 4.

${ }^{78}$ ACdV, Confederación Católica de Padres de Familia. Claudio Coello, 32 (Madrid). Correspondencia en el año de 1935, «Carta de F. Carro a José $\mathrm{M}^{\mathrm{2}}$ Torre de Rodas, Valladolid, 7 de diciembre de 1935 ».

${ }^{79} \mathrm{ACdV}$, Círculos de Estudios celebrados en el curso de 1935 a 1936 por la Asociación Católica de Padres de Familia de Valladolid, «Carta de F. Carro a las parroquias».

80 Programa del Cursillo:

I- Definición oficial de la Acción Católica y su explicación.

II- Fin último propio de la Acción Católica. Fines próximos. Fin inmediato.

$\mathrm{El}$ asociacionismo en la iglesia

Hispania Sacra 50 (1998) 
Pero de nuevo se recomienda el aumento del número de circulistas: «Es seguro que asistirán los circulistas del pasado curso. Pero no es bastante. Es necesario, además, que se aumente el número de circulistas y que su intervención en el desarrollo de los temas sea mayor» ${ }^{81}$. Dicho número, para el curso 1935 1936, incluyendo el Secretariado técnico y el Consiliario, es muy escaso: $29^{82}$.

2) En febrero de 1935 se inaugura la Academia para adultos en las Delicias, para, a instancias del arzobispo Gandásegui, «procurar a los jóvenes de aquella populosa barriada, una amplia cultura general basada en la moral y religión católica ${ }^{83}$. De la formación religiosa se encarga el profesor del Seminario y párroco de la Magdalena, Valerio Caudevilla, mientras que «la parte cultural profana está a cargo del maestro manjoniano don Paulino Vico Rojas». El número de alumnos en este año es de 45 . En julio de 1935, cuando el curso ya ha finalizado, se expone el gran éxito de la Academia: ha sido preciso restringir el número de alumnos y de horas impartidas, debido a la gran demánda suscitada ${ }^{84}$.

2.4. Las labores de defensa frente al avance del laicismo (1933-1936). La Mutualidad de Padres de Familia:

La aprobación de la Ley de Confesiones y Congregaciones Religiosas extiende un fuerte temor entre los colegios religiosos vallisoletanos. Esto lleva a Gandásegui, en conformidad con los acuerdos de las Conferencias de noviembre de 1932 y junio de $1933^{85}$, a potenciar la creación, el 11 de agosto de ese

III- Necesidad de la Acción Católica. Obligatoriedad de la Acción Católica.

IV- Organización general de la Acción Católica.

V- "Hombres de Acción Católica ".- Organización de esta rama oficial. Su relación con la Asociación Calólica de Padres de Familia.

En ibid., «Asociación Católica de Padres de Familia de Valladolid. Circulo de Estudios.- Curso de 1935-1936. Segunda Etapa. Cursillo breve sobre Acción Calólica».

${ }^{81}$ ACdV, Asociación Católica de Padres de Familia de Valladolid. Circular núm. 6, I octubre 1935, pág. 4

\$2 lbid., «Círculos de Estudios...», op. cit.

${ }^{83}$ En ACdV, Asociación Catolica de Padres de Familia de Valladolid. Circular núm. 4, I abril 1935, păg. 4.

${ }^{84}$ ACdV, Asociación Católica de Padres de Familia de Valladolid. Circular núm, 5, 11 julio 1935, pág. 6 .

${ }^{85}$ Ver CÁRCEl ORTí, V., Actas de las Conferencias de Metropolitanos españoles (1921-1965), Ed. BAC, pp. 289 y 391 . La idea de defender la educación impartida por las Congregaciones docentes por parte de los Padres de Familia mediante Asociaciones mutuales surge en la de noviembre de 1932, y se explicita más claramente (organización, ventajas,...) en la de junio de 1933.

Las Mutualidades serán aconsejadas de nuevo por los Metropolitanos en la Conferencia de noviembre de 1934, ibid., pp. 346-347. 
mismo año, de la Mutualidad de Padres de Familia, amparada en la nueva Ley, y pensada para servir de estrategia en el mantenimiento de la enseñanza religiosa en esta ciudad ${ }^{86}$. Su finalidad es velar por la educación cristiana de los niños mediante la creación de «escuelas, colegios, internados, centros de cultura secundaria y superior y residencias de estudiantes, atendidos y vigilados por profesores católicos, como medio esencial para atender a la función educativa, fin y fundamento de esta Mutualidad ${ }^{87}$.

La Mutualidad, reconocida por la autoridad municipal y en estrecha relación con el prelado, pretendía hacerse cargo de los Colegios de Religiosas de la diócesis, en caso de aplicarse estrictamente la Ley, cosa que no ocurrióo ${ }^{88}$. Pese a ello, la prohibición de la enseñanza religiosa hizo que la Mutualidad se hiciese cargo de los Colegios Compañía de María (Enseñanza), Carmelitas del Museo e Hijas de Jesús. Las religiosas tuvieron que despojarse del hábito para dar clase, se incorporaron profesores seglares y, gracias a la Mutualidad, la enseñanza religiosa pudo seguir impartiéndose en la ciudad ${ }^{89}$. La Mutualidad de Padres de Familia observa que, no obstante estos inconvenientes, los inspectores en Valladolid, excepto algún caso aislado, se comportaron conforme a la legalidad, tendente a procurar esa sustitución de la enseñanza religiosa, pero

86 «Conocidos son de todos vosotros la dirección acertada y segura, el fuerte impulso, el constante estímulo y la protección eficaz que recibimos del Rcpresentante de la Iglesia en esta Diócesis, amadísimo Prclado nuestro. Gracias a él fue harto fácil la labor porque apartó de nucstro camino todas las dificultades que se opusicron y pudimos hacemos cargo (...) de los tres Colegios en que educaban y siguen educándose nucstras hijas: el de la Compañía de María, cl de las Carmelitas del Musco, el de las Hijas de Jesús», ACdV, Copia de movimientos de fondos y memorias, «Memoria de la Mutualidad de Padres de Familia de Valladolid correspondiente al ejercicio económico de 1933 a 1934». La constitución de todas las Mutualidades responde a las ventajas que se extraen de los proyectos aportados por la Federación de Amigos de la Enseñanza de Madrid, y la Federación Catalana de Enseñanza Libre; ver CÁRCEL ORTí, V., op. cit. pp. 305-308.

${ }^{87}$ ACdV, Reglamento de la Mutualidad de Padres de Familia, pág. 1. La composición es la siguiente:

Presidente: ...................................... Fernando Carro

Viccpresidente: ............................. Pascual Pinilla Jiméncz

Secretario: ................................... Eugenio Labrador

Tesorero: ....................................... Femando Presa

Contador: ...................................... Anastasio Cristóbal

88 «[Dios] otorgó a esta Mutualidad la honrosa misión de ser la salvaguardia de todos los Colegios de Religiosas de csta Dícesis. Vosotros sabéis que estaba todo dispuesto para hacernos cargo de los nucve Colegios de Religiosas (5 en Valladolid, 1 en Medina del Campo, otro en Nava del Rey, otro en Tordesiltas y otro en Rueda), en el caso de haberse aplicado rígidamente la Ley de Congregaciones Religiosas. Gracias a Dios no hizo falta», en ACdV, Copia de movimientos de fondos y memorias, «Memoria de la Mutualidad de Padres de Familia de Valladolid correspondiente al ejercicio económico de 1933 a 1934».

89 Ver por cjemplo el caso del Colegio de la Compañía de María, en ACdV, ZuRRo LLORENTE, E., op. cít., pág. 16.

El asociacionismo en la iglesia

Hispania Sacra 50 (1998) 
sin excesos ni tiranías. Este hecho, más la actuación de la misma, hicieron que pese a las amenazas, la enseñanza religiosa pudiese abrirse camino ${ }^{90}$.

Por su parte, la Asociación Católica de Padres de Familia, aparte de tener que restringir sus reuniones y su labor de propaganda en los pueblos por miedo a ser interpretadas como clandestinas por la autoridad, hubo de suspender las clases de adultos que se impartían en la escuela de las Delicias ${ }^{91}$.

Tras el triunfo de la izquierda en las elecciones de febrero de 1936, el anticlericalismo crece en Valladolid ${ }^{22}$. Esto hace que la Asociación vea reducida su "vida social»: ésta se reducirá únicamente a la Misa de Comunión Mensual, a las sesiones quincenales de la Junta Directiva y las semanales del Círculo de Estudio ${ }^{93}$.

En lo referente a la enseñanza religiosa, dos eran las "amenazas " que cundían sobre la misma: la pretendida sustitución de la enseñanza dada por las Congregaciones Religiosas, para lo que se creaban 5.300 plazas de maestros, anunciándose a la vez la pronta creación de otras 5.000 más, y la que hacía referencia al Certificado Escolar de Estudios Primarios. No dejaba de preocupar tampoco el «laicismo efectivo en las escuelas oficiales» ${ }^{94}$. La Asociación intenta intervenir en el nombramiento del Tribunal de Cursillos para la selección de los Maestros, pero la Dirección general de la Enseñanza los nombró directamente; «y casi otro tanto podemos decir del correspondiente al Certificado Escolar de Estudios Primarios»"s. Los ataques adquieren especial virulencia en el caso del Colegio Hijas de Jesús (Jesuitinas): en la fiesta del Sagrado Corazón (junio de 1936), fue asesinado D. Juan Sainz, miembro de la Asociación Católica de Padres de Familia de Valladolid encargado de defender el colegio, «hiriendo de gravedad a su hijo, cuando éste iba camino del hospital a ver a su padre»96. Posteriormente se decretó el cierre del Colegio, por lo que éste pasó a manos de la Asociación de Padres de Familia, y para separarlo del

90 Ver ACdV, Copia de movimientos de fondos y memorias, «Mutualidad de Padres de Familia de Valladolid. Memoria Correspondiente al curso 1935-36m, pág. 1.

$91 \mathrm{ACdV}$, Asociación Católica de Padres de Familia de Valladolid. Memoria correspondiente al año 1936, pág. 1.

92 «Cetebradas las elecciones, y dueñas del Poder las izquierdas, renovóse la persecución que había quedado paralizada en 1933 (...) los Decretos, las Ordenes y Circulares de Instrucción Pública, que empezaron a publicarse en el mismo mes de febrero, y se sucedian sin interrupción, eran de una gravedad mucho mayor que los que rigieron durante cl primer bienio de la República. Jamás la enseñanza católica había sido combatida tan meditada y sañudamente», en (ACdV), Asociación Católica de Padres de Familia de Valladolid. Memoria correspondiente al año 1936, pág. 1.

93 Ibid.

94 (ACdV), ibid., pág. 2.

95 lbid.

${ }^{96}$ lbid., pág. 17. 
Convento, se hubo de levantar un tabique. Antes de los sucesos del 18 de julio, el alcalde García Quintana se presentó junto a un profesor de la Normal de Maestros, «coaccionando a las religiosas para que dejaran el Centro»; la intervención de Melancio Calvo, miembro de la Asociación, logró detener este intento ${ }^{97}$. «El Arzobispo, Monseñor Gandásegui, nos ordenó que dejáramos el santo hábito, y vestidas de seglar, continuamos dando clase a los niños sin ser molestadas más, hasta que estalló el Movimiento»98.

\subsection{La lucha contra la Coeducación ${ }^{99}$ :}

Aborrecida por los medios católicos, la coeducación será atacada por la Asociación con especial fuerza. Ya en el informe enviado por ésta el 3 de enero de 1933 al Presidente de la Comisión dictaminadora del Proyecto de Ley de Bases sobre la Reforma de la primera y segunda enseñanza, se decía: «Nada dicen las Bases del problema de la coeducación. Nosotros pedimos una declaración legal definitiva sobre esta cuestión en sentido contrario a la norma seguida hasta el presente; porque la coeducación no es regla general adoptada en el mundo culto, es antipedagógica, y no está autorizada por la Constitución»100. La Asociación afirma que por entonces se asumió la coeducación en varios colegios, debido a que «estábamos entonces en época de sectarismo exaltado».

Por todo ello, se acoge positivamente la Orden prohibiendo la coeducación en la Primera Enseñanza dada por el ministro de Instrucción Pública el 3 de agosto de 1934, aunque siempre se aspira a más, esto es, a abolirla definitivamente y en todos los centros ${ }^{101}$ : «Hemos de agradecer al señor Villalobos su acertada Orden; mas persuadidos de que la coeducación es más perniciosa en el periodo de la adolescencia que en el de la niñez, habremos de proseguir la campaña emprendida, hasta conseguir sea desterrado de los Institutos y de las Normales este exótico, erróneo y funesto sistema educativo» ${ }^{102}$. En abril de

\footnotetext{
97 Ibid., pág. 18.

98 Ibid., pág. 17.

99 Ver ACdV, Asociación Casólica de Padres de Familia de Valladolid. Circular núm. 2, 30 octubre 1934, pág. 4.

100 Por su parte, ya la Confederación había destacado que la coeducación se había desterrado de los países más cultos, y que sólo se mantenía en los Estados Unidos y en la Unión Soviética, con efectos devastadores. Ibid.

101 En la Conferencia de Metropolitanos celebrada los días 15-18 de noviembre de 1934, se señala a los Padres de Familia en uno de los puntos tratados: «Téngase también presente el Decreto de 3 de agosto sobre la coeducación en la primera enseñanza», en Cárcel Orti, V., Actas de las Conferencias de Metropolitanos Españoles (1921-1965), Ed. BAC, 1994, pág. 348.

102 Ver ACdV, Asociación Católica de Padres de Familia. Circular núm.2., 30 de octubre de 1934, pág. 4.
}

El asociacionismo en la igtesia

Hispania Sacra 50 (1998) 
1935 la Asociación recibe con agrado la proposición sobre Reforma de las Escuelas Normales, presentada en el Congreso por la Srta. Bohigas, los Sres. Gil Robles, Royo Villanova, Alonso de Armiño, Blanco, Calderón, Vélez, Izquierdo Jiménez y Del Moral. En ella, entre otras disposiciones, se suprime la Escuela Normal Unica y se restablecen las Escuelas Normales de Maestros y Maestras. La Asociación vallisoletana envió un telegrama de felicitación a la Stta. Bohigas, y otro al ministro de Instrucción Pública para procurar su apoyo, por lo que espera que la proposición salga adelante ${ }^{103}$.

Aún así, prosiguen las llamadas a luchar contra la coeducación en Valladolid, pues aunque persiste en los Institutos de Segunda Enseñanza, es posible erradicarla por completo «y sin grave detrimento ni coste, por tener dos Institutos, y poder dedicar uno a cada sexo»104.

\subsection{La lucha contra el sectarismo ${ }^{105}$ :}

En la segunda circular de la Asociación, perteneciente a octubre de 1934, la Asociación expone su «objetivo inmediato»: «acabar con el sectarismo en las escuelas primarias oficiales». En este llamamiento, además de condenar la actitud laicista de determinados maestros de las escuelas oficiales, se lamentan de que varios hijos de padres asociados, que, por carecer de medios suficientes tienen que mandar a éstos a dichas escuelas, se vean afectados por esa enseñanza. Para evitarlo, se toman dos medidas: que los padres que envíen a sus hijos a las escuelas oficiales comuniquen a la Asociación sus nombres y los de sus hijos, «escuelas a que éstos asisten y maestros que las regentan, $o$, lo que es mejor aún, que se pasen por nuestras oficinas de once a una»; por otro lado, para llevar a cabo una «labor eficaz», los demás asociados están llamados a organizar las Secciones parroquiales «en grupos de diez con uno al frente», por lo que se ruega a aquellos que puedan disponer de una hora al mes, den su mombre o se presenten del mismo modo en las oficinas.

Junto con esta condena del laicismo en la escuela, también la Asociación arremete contra el nuevo plan de estudios, «Plan Villalobos», por considerar

${ }^{103}$ ACdV, Asociación Católica de Padres de Familia de Valladolid. Circular núm. 4, I abril J935, pág. 3.

${ }_{104}$ Ibid.

105 ACdV, Asociación Católica de Padres de Familia de Valladolid. Circular núm. 2, 30 octubre 1934, pág. 2. 
que favorece más a la enseñanza oficial que a la privada ${ }^{106}$. Aunque reconocen que dicho plan posee importantes ventajas («ha introducido en los estudios del Bachillerato el plan cíclico y gradual y ha intensificado el estudio de las disciplinas humanísticas»), critican el artículo 22, pues, según la Asociación, marginaba a la enseñanza privada, ya que a sus alumnos les exigía más exámenes que antiguamente, «mientras que a los alumnos oficiales se les dispensa de ellos» ${ }^{107}$.

\subsection{La rama de Hombres de Acción Católica de Valladolid:}

En otro orden de cosas, la Asociación de Padres de Familia de Valladolid, como ocurre en el resto de la geografía española, sirve de base para la constitución de la rama de «Hombres de Acción Católica». La Asociación se ofreció a este cometido, y en 'el mes de marzo de 1936 participó en la reunión celebrada en Madrid, a la que asistieron los representantes de las distintas Asociaciones. En ella se acordaron unas conclusiones que fueron elevadas al Consiliario general de la Acción Católica y a los respectivos prelados, «que son quienes en su día determinarán la extensión y modo en que han de aplicarse en cada Diócesis las instrucciones del Consejo Superior de la Rama de "Hombres de Acción Católica ", que nuestras Asociaciones habrán de atender cumplidamente» ${ }^{108}$.

Pero se deja bien claro que pese a este proyecto, la entidad jurídica «Asociación Católica de Padres de Familia», subsistiră, «con aquellas modificaciones que se estimen oportunas, enlazada con la Acción Católica y con sus fines específicos, según acuerdo de los Metropolitanos»109.

Los trabajos de la Asociación vallisoletana en este sentido son importantes: en 1936, da cuenta de que se halla esperando únicamente la orden del prelado. Además, ya ha preparado un proyecto de Reglamento para la Unión Diocesana de Hombres de Acción Católica, «cosa que no sabemos haya hecho hasta el presente ninguna otra Asociación; por lo cual, probablemente, servirá de guía para la redacción del Reglamento oficial que se apruebe, lo que constituirá un

\footnotetext{
106 «Por lo que a nosotros toca, jamás podrá satisfacemos plan alguno, sino incluye entre sus dis ciplinas una enseñanza religiosa (...) y destierra ese sistema eró́neo y gravemente dañoso llamado Coeducación (...)», ibid.

107 ACdV, Asociación Católica de Padres de Familia de Valladolid. Circular núm. 3, 7 enero 1935 , pág. 3.

${ }^{108}$ (ACdV), Asociación Católica de Padres de Familia de Valladolid. Memoria correspondiente al año 1936, pág. 2.

109 Ibid.
}

El asociacionismo en la iglesia

Hispania Sacra 50 (1998) 
mérito para nuestra Asociación de Valladolid, si bien hasta que ese día llegue, también nuestro trabajo habrá resultado infructuoso» ${ }^{10}$.

\subsection{La labor de propaganda y sus parcos resultados:}

Aparte de las dificultades vistas en los primeros momentos, sólo tenemos noticias exhaustivas de esta labor en 1934'11. Parece que por entonces la Asociación ha experimentado cierto auge en esta faceta, si bien es cierto que la propaganda es más efectiva en los pueblos que en las ciudades: «La campaña de propaganda realizada por nuestra Asociación en los pueblos de la Diócesis ha sido intensísima. Se han visitado veintidós pueblos, de los cuales, solamente en cinco no fue posible ${ }^{112}$, por circunstancias especiales (en algunos de ellos transitorias), constituir la Delegación correspondiente»113. A la altura de 1934, la Asociación cuenta con Delegacionès en 23 pueblos ${ }^{114}$.

Se pone como ejemplo magistral de propaganda las realizaciones emprendidas en la Delegación de Zaratán, gracias al presidente de la misma, Timoteo Martín Lara, que, junto con el párroco Justo Adalia y el presidente de la Juventud Católica, Cipriano Camicero, abrió el 16 de julio de 1934 la «primera escuela católica para la niñez», donde los niños reciben educación moral y religiosa durante dos horas diarias. Aún así, se hacen ver las carencias de material que aún persisten, para lo que se pide la colaboración desinteresada de los padres de familia ${ }^{115}$.

I10 Infructuoso, seguramente, por la interrupción que supuso el estallido de la Guerra Civil. Ibid.

III Extraídas de ACdV, Asociación Católica de Padres de Familia de Valladolid. Circular núm. 1 . J Julio 1934, pág. 3.

${ }^{1 / 2}$ Simancas, Alaejos, Sieteiglesias, Pozaldez y Tudela de Ducro.

113 Ibid.

114 Enumerados en orden cronológico de constitución, son: Mucientes

Cigales Wamba

Pozal de Gallinas Castrodeza

Serrada

Camporredondo

Villanubla

Santiago del Arroyo

La Parrilla

Portillo

La Seca

Arrabal de Portillo

Rueda San Miguel del Arroyo

Geria La Pedraja del Portillo

Tordesillas Aldeamayor de San Martín

Bercero La Cistérniga

Fucnsaldaña

115 ACdV, Asociación Católica de Padres de Familia de Valladolid. Circular núm. 2, 30 octubre 1934, pág.. 3. 
En abril de 1935 sigue en auge la creación de Delegaciones en los pueblos, pues la propaganda se extiende a 10 más $^{16}$. En julio prosigue de forma inten$\mathrm{sa}^{117}$, pero experimenta un claro estancamiento en el verano («no es el verano época propicia para la propaganda», se dirál18): se crean dos Delegaciones (Nava del Rey y Torrecilla de la Orden) y se reorganiza la de Medina del Campo ${ }^{119}$.

Pero pese a las apariencias, la realidad es muy otra. El presidente en funciones en 1934, Juan G. Regueral, hace ver que por un lado marcha el número de Delegaciones creadas, y por otro la calidad de las mismas; si el primero aumenta, el segundo no parece seguir ese mismo camino; así, en junio de 1934, se informa a Madrid: «aunque lamente sentirme bastante pesimista en esta carta, creo del caso hacerle presente que muchas de estas delegaciones son de dudosa labor eficaz y acabo de recibir carta del Presidente de una de las establecidas esta última temporada que manifiesta no aumentar el número de socios y negarse a cotizar. Desgraciadamente se siente poco fervor» ${ }^{120}$.

Y es que las dificultades en determinados pueblos son grandes: por ejemplo, tenemos noticia de que la Delegación constituida en Medina del Campo es tan débil, que en julio de 1935 el presidente tiene que reunirse allí con $\mathrm{F}$. Carro, el Arcipreste y dos miembros de la Delegación (St. Puertas y Sr. Hervella), «para tratar de hacerla revivir»; la reunión es positiva, y se acuerda organizar de nuevo la Delegación ${ }^{121}$. Parece tan deficiente el estado de las Delegaciones en los pueblos, que en diciembre de 1935 F. Carro comunica a Torre de Rodas que sólo la de Zaratán funciona, estando las demás prácticamente paralizadas ${ }^{122}$.

Que la cotización en el campo era francamente negativa, lo demuestra, por ejemplo, el Movimiento de fondos de 1936: 6.154 pesetas por aportación en

116 Ciguñuela, Robladillo, Villán de Tordesillas, Velliza, Matilla de los Caños y Valdestillas, Renedo, Laguna de Duero, Boecillo y Villabátiez, en ACdV, Asociación Carólica de Padres de Familia de Valladolid. Circular núm. 4, 1 abril 1935, pág. 4.

117 Puente Duero, Villanueva de Duero, Pozaldez, Rodilana, Matapozuclos, Villavieja del Cero, Marzales, San Miguel del Pino y Villamarciel, en ACdV, Asociación Católica de Padres de Familia de Valladolid. Circular núm. 5, 11 julio 1935, pág. 2.

118 ACdV, Asociación Católica de Padres de Familia de Valladolid. Circular núm. 6, I octubre 1935 , pág. 4.

119 Ibid.

120 ACdV, Asociación Católica de Padres de Familia. Correspondencia recibida y contestada de la Confederación en el año de 1934, «Carta de Juan G. Regueral a José M* Torre de Rodas, Valladolid, 18 de junio de 1934».

121 ACdV, Confederación Católica de Padres de Familia. Claudio Coello, 32 (Madrid). Correspondencia en el año de 1935, «Carta de Juan G. Regueral a José $\mathrm{M}^{\mathrm{a}}$ Torre de Rodas, Valladolid, 29 de jutio de $1935 \%$.

122 ACdV, ibid., «Carta de F. Carro a José $M^{a}$ Torre de Rodas, Valladolid, 7 de diciembre de 1935».

El asociacionismo en la iglesia

Hispania Sacra 50 (1998) 
forma de cuotas provenientes de la capital, frente a las 16 pesetas de los socios de los pueblos ${ }^{123}$.

Como decíamos, «la propaganda en la capital ha sido menos intensa que en los pueblos»124. Aunque el desánimo cunde entre los Padres de Familia por este fracaso, se exhorta a combatir a su peor enemigo: los socialistas y sus organizaciones de Padres y Amigos de la Escuela.

\subsection{Una estrategia posibilista: la Asociación en los Consejos escolares ${ }^{125}$ :}

Ya los Metropolitanos, en la Conferencia de noviembre de 1934, habían aconsejado a los Padres de Familia la necesidad de estar representados en los Consejos Locales de primera enseñanza, para impedir la acción antireligiosa de los maestros oficiales; la oportunidad la tenían en las próximas elecciones de vocales para los mismos ${ }^{126}$; la estrategia emprendida por F. Carro (ahora Secretario de la Acción Católica vallisoletana) a este respecto en Valladolid, es inteligente y claramente accidentalista. La Asociación de Padres de Familia quedaba excluída de la elección de vocales para el Consejo Provincial y Local; pero no así la Mutualidad, pues aunque en la práctica es confesional, no lo demuestra en su título, "y como en la certificación pedida por el Gobierno Civil de estar inscrita en el Registro de asociaciones nada dice tampoco, parece ser que ba pasado».

F. Carro informa a Torre de Rodas que «la victoria puede darse por alcanzada, porque aun en el caso dificil que desestimasen la propuesta (me dicen que ya están extendidos los nombramientos), les tenemos preparada otra sorpresa...definitiva»; y es que se ha creado una Sociedad Cultural de Padres de Familia, «perfectamente aconfesional en sus Estatutos y haría entonces valer sus derechos indiscutibles». La estrategia es perfecta: «esta Sociedad es sólo aconfesional en apariencia, y además, una ficción legal, porque solamente actuará en aquellos casos, como el presente en que no pueda hacerlo la Asociación; si alguna vez actúa, lo hará en presencia del Consiliario de la Asociación y se disolverá a la menor indicación del Prelado». Se crea dicha sociedad en septiembre de 1934, siendo el fundador D. Alvaro Pascual, y en los estatutos se determina su fin: «promover, difundir y proteger la cultura general y,

\footnotetext{
123 ACdV, Movimientos de fondos. 1936.

124 Ibid.

125 ACdV, Asociación Católica de Padres de Familia. Correspondencia recibida y contestada de La Confederación en el afto de 1934, «Carta de F. Carro a José $\mathbf{M}^{\mathrm{a}}$ Torre de Rodas, Valladolid, 26 de septiembre de 1934».

126 Cárcel Ortí, V., Actas..., op. cit., pág. 348.
} 
especialmente, la escolar, utilizando para ello todos aquellos medios que se estimen beneficiosos y autoricen las leyes civiles vigentes» ${ }^{127}$.

$Y$ es que el fin pretendido no es otro que la victoria de la Asociación, «poniendo para ello todos los medios que tenga a su alcance». La Sociedad cum ple su misión, pues no celebra ninguna reunión más allá de la fecha de su constitución.

Es preciso mantener esta estrategia en secreto: «Una indicación final. No es conveniente dar a la publicidad nuestro éxito en las elecciones de los Consejos escolares (...) pues acaso nos creara dificultades para alcanzar el objetivo in mediato que supongo hemos de perseguir: la desaparición total del sectarismo en las pocas escuelas nacionales que aquí le sufren». Como anunciaba F. Carro, el triunfo obtenido por la Asociación en las elecciones de vocales para los Consejos Provincial y Local es claro; ahora se plantea un objetivo doble: «acabar con la propaganda sectaria de unos pocos maestros», y «ver de suprimir la Coeducación en las Escuelas Municipales» ${ }^{128}$.

\subsection{Contra el cine inmoral:}

La lucha por la «moralidad del cinematógrafo» es un aspecto en el que ya la Confederación madrileña hace bastante hincapié. Alentada por ésta, la Asociación vallisoletana se entrega también a la tarea. Pero las dificultades para realizar una campaña de este tipo en Valladolid son expuestas en 1935 por el presidente, Juan G. Regueral, en carta a Torre de Rodas: «(...) este importantisimo asunto tiene poca aplicación aquí, pues no hay salones especiales de los que podamos hacer relación. (...) únicamente existe el de la Casa Social Católica que hubo de cerrarse por no cubrir gastos con la escasa consurrencia que tenía; por esto aquí ya venimnos preocupándonos de hacer en días determinados en algún teatro, de acuerdo con el Empresario sesiones en que pueda garantizarse la moralidad de las películas. En tal sentido marchamos de acuerdo

${ }^{127}$ ACdV, Asociación Cultural de Padres de Familia. Documentación de la misma, «Estatutos de la Sociedad Cultural de Padres de Familia». El domicilio se haya situado en la Calle Núñez de Arce, $\mathbf{n}^{\circ} 38, y$ la composición de la Junta Directiva es la siguiente:

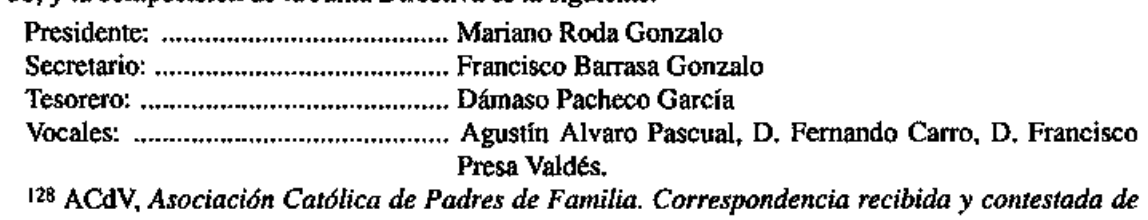
la Confederación en el año de 1934, «Carta de F. Carro a José $\mathbf{M}^{\mathbf{3}}$ Torre de Rodas, Valladolid, 29 de octubre de 1934».

El asociacionismo en la iglesia

Hispania Sacra 50 (1998) 
con la Junta Diocesana de Acción Católica que también se preocupa de lo mismo». Aparte de ciertas películas proyectadas en el teatro Calderón, se puede contar con el cinematógrafo particular del antiguo salón de los KostKas, bajo la dirección de los P.P. Jesuitas ${ }^{129}$.

A la hora de la proyección de películas en el Teatro Calderón, la Asociación vallisoletana pide informes a Madrid, donde se «disponde un archivo de películas clasificadas en orden a su moralidad» ${ }^{130}$. Para dicha labor se constituye la Sociedad «Ediciones Cinematográficas Españolas», y siguiendo los consejos de la Confederación, la Asociación vallisoletana se dispone a la suscripción de acciones para $\mathrm{ECE}^{131}$. Por otra parte, se crea desde Madrid la revista Filmor, de propaganda en favor de la moralidad del cine; la Asociación vallisoletana la recibe gustosamente y realiza la pertinente propaganda de la misma $^{132}$.

Para informar a Madrid acerca de las películas que se estrenan en la capital castellana, se presta Diario Regional; este perí́dico católico acepta el servicio de cambio con la revista de la Confederación madrileña, Hogar ${ }^{133}$.

Mucha importancia adquiere la Semana contra el Cine inmoral, de octubre de 1935; ya desde principios de junio, la Asociación vallisoletana está en contacto con la juventud femenina para esta celebración ${ }^{134}$, y Torre de Rodas les advierte: «es muy importante que presten una cooperación activa los Padres de Familia, y que la Asociación no aparezca separada de este movimiento» ${ }^{135}$, a lo que responde afirmativamente Juan G. Regueral ${ }^{136}$. Éste le comunica las gestiones que está haciendo en favor de los Padres de Familia, de tal manera que ha gestionado la llegada a Valladolid de un miembro de la Confederación para impartir una conferencia en los actos de dicha Semana: «Mi idea sería que el orador designado fuera persona relevante dentro de la Confederación, como

129 ACdV, Confederación Católica de Padres de Familia. Claudio Coello, 32 (Madrid). Correspondencia en el año de 1935, «Carta de Juan G. Regueral a José $\mathbf{M}^{\mathbf{3}}$ Torre de Rodas, Valladolid, 18 de enero de 1935»; como es natural, desde Madrid, Torre de Rodas les exhorta a potenciar el asunto de] cine: «Carta de José $\mathrm{M}^{\mathrm{a}}$ Torre de Rodas a Juan G. Regueral, Madrid, 21 de enero de 1935 ».

130 ACdV, jbid., "Carta de José MP Torre de Rodas a Juan G. Regueral, Madrid, 28 de febrero de 1935».

131 ACdV, Confederación Católica de Padres de Familia. Claudio Coello, 32 (Madrid). Correspondencia en el año de 1935, «Carta de José $\mathrm{M}^{\mathrm{a}}$ Torre de Rodas a Juan G. Regueral, Madrid, 18 de junio de $1935 \%$.

132 ACdV, ibid., «Carta de José $\mathbf{M}^{\mathbf{a}}$ Torre de Rodas a Juan G. Regueral, Madrid, 24 de junio de 1935», y repuesta (Valladolid, 27 de junio de 1935).

133 ACdV, ibid., «Carta de José $\mathbf{M}^{2}$ Torre de Rodas a Juan G. Regueral, Madrid, 12 de jumio de 1935».

134 ACdV, ibid. «Carta de Juan G. Regueral a Jose $\mathrm{M}^{\mathrm{2}}$ Torre de Rodas, Valladolid, 10 de junio de 1935».

135 ACdV, ibid. «Carta de José M Torre de Rodas a Juan G. Regueral, Madrid, 18 de junio de 1935».

136 «Desde luego marchamos de acuerdo y no hemos sido ajenos a la iniciativa de la organización de la Semana contra el Cine inmoral que se celebrará aquí el próximo octubre», en ibid." «Carta de Juan G. Regueral a José $\mathrm{M}^{\mathrm{a}}$ Torre de Rodas, Valladolid, 27 de junio de 1935n. 
por ej. V., y no es lisonja» ${ }^{137}$. Torre de Rodas se muestra conforme ${ }^{138}$, pero la enfermedad de su hijo le impide participar en la Semana; será sustituído por Florentino Carreño ${ }^{139}$.

Los resultados de la Semana son muy favorables, por lo que Juan G. Regueral espera «mayor concurrencia y disposición para el trabajo» ${ }^{140}$.

\subsection{En favor del Magisterio católico:}

Las labores de la Asociación Vallisoletana también se encaminan hacia la potenciación del Magisterio católico. Este aspecto encuentra una doble vía de actuación, -siempre unida a la Cofederación-:

1- La campaña de marzo de 1935: en ella, la Asociación vallisoletana, y por iniciativa del Vocal D. Rafael López Sánchez, decide enviar un telegrama al Ministro de Instrucción Pública «en nombre de esta Asociación y en beneficio de los maestros de tres mil pesetas para que no sufran postergación en relación con los de grado profesional» ${ }^{141}$. Se expone a Torre de Rodas Ia conveniencia de que las demás Asociaciones apoyen esta iniciativa; pero no creyendo oportuno el momento, por estar ocupadas en otros asuntos, el secretario madrileño contesta dando el visto bueno al telegrama, aunque sin reclamar el apoyo de las demás Asociaciones ${ }^{142}$.

2- La labor de organización y unión de los maestros católicos: recomendada por Torre de Rodas, pues en Madrid existe una Federación Católica de Maestros Españoles (reunión de «las pocas Asociaciones que de ellos existen»), se pretende que Valladolid también les reúna: «Yo les ruego a Vds. se preocupen de reunirlos, expresándoles la satisfacción con que la Asociación de Padres de

137 ACdV, Confederación Católica de Padres de Familia. Claudio Coello, 32 (Madrid). Correspondencia en el año de 1935, «Carta de Juan G. Regucral a José M $^{2}$ Torre de Rodas, Valladolid, 20 de julio de 1935."

138 Ibid, «Carta de Jose $\mathbf{M}^{\mathrm{z}}$ Torre de Rodas a Juan G. Regueral, Madrid, 23 de julio de 1935.» La conferencia será el 26 de octubre (la Semana es del 21 al 27), antes de la del Sr. Pemán, y el tema, de libre elección: id., «Carta de Juan G. Regueral a Jose $\mathbf{M}^{\mathbf{t}}$ Torre de Rodas, Valladolid, 13 de septiembre de $1935 »$, id. del 24 de septiembre de 1935 . Al final, el Sr. Pemán no pudo intervenir, por lo que fue sustituído por José $\mathrm{M}^{a}$ Valiente, id., «Carta de Juan G. Regueral a José $\mathrm{M}^{a}$ Torre de Rodas, Vajladolid, 18 de octubre de 1935 .

139 ACdV, Confederación Católica de Padres de Familia. Clandio Coello, 32 (Madrid). Correspondencia en el año de 1935, «Carta de Juan G. Regueral a José $\mathrm{M}^{\mathrm{a}}$ Torre de Rodas, Valladolid, 29 de octubre de 1935 ".

140 Ibid.

141 ACdV, ibid., «Carta de Juan G. Regueral a José M"a Torre de Rodas, Valladolid, 26 de marzo de $1935 »$.

142 ACdV, ibid., «Carta de José $\mathbf{M}^{\mathrm{n}}$ Torre de Rodas a Juan G. Regueral, Madrid, 29 de marzo de 1935».

El asociacionismo en la iglesia

Hispania Sacra 50 (1998) 
Familia vería que ellos formaran también una Asociación. Si son pocos los decididos, podría constituir una Delegación, adherida a la Federación. Una vez constituída la Asociación o Delegación, deben ponerse al habla con el Comité Central de la Federación ${ }^{143}$.

La iniciativa que se toma en Valladolid, potenciada por Rafael López Sánchez, es la de reorganizar la Asociación de maestros católicos; ésta ya existía en nuestra ciudad, pero está «muerta de hecho pues no volvió a celebrar reuniones». El 31 de marzo, en una reunión del embrionario núcleo de maestros, se acuerda nombrar nueva Junta Directiva y modificar el Reglamento, tomando como modelo el madrileño ${ }^{\mathrm{I} 4}$. Para ello, desde la Confederación se establece contacto con el Secretariado de la Federación Católica de Maestros, con el que se relacionará la Asociación vallisoletana para todas las dudas que posea ${ }^{145}$.

\section{ESTALLA LA GUERRA CIVIL: EN FAVOR DEL ALZAMIENTO, DE LA ENSEÑANZA Y MORAL CRISTIANAS ${ }^{146:}$}

Los trabajos llevados a cabo en 1937 lo fueron exclusivamente por la Junta Directiva, pues no se quería distraer a los asociados de sus importantes tareas en pro de «la Santa Cruzada actual» ${ }^{147}$. La situación por la que atraviesa la Asociación en este año es mucho mejor que la de las demás, seguramente por el tempranísimo triunfo de los sublevados en Valladolid ${ }^{148}$. Para contribuir a la "defensa del Movimiento Salvador de nuestra Patria», la Junta Directiva contribuye a la venta y difusión del folleto del Cardenal Primado (Isidro Gomá), $E l$ Caso de España. Defensa del nuevo régimen que pasa por la abolición de la legislación republicana anterior: «(...) se iniciaron una serie de gestiones con el fin de que fueran derogadas las leyes sobre el Matrimonio civil y el Divorcio» ${ }^{149}$.

143 ACdV, Confederación Católica de Padres de Familia. Claudio Coello, 32 (Madrid). Correspondencia en el año de 1935, «Carta de José $\mathrm{M}^{\mathrm{a}}$ Torre de Rodas a Juan G. Regueral, Madriđ, 27 de marzo de 1935».

144 ACdV, Confederación Catolica de Padres de Familia. Claudio Coello, 32 (Madrid). Correspondencia en el año de 1935, «Carta de Juan G. Regueral a José $\mathrm{M}^{\mathrm{a}}$ Torre de Rodas, Valladolid, 1 de abril de 1935".

145 Ibid., «Carta de Torre de Rodas a Juan G. Regueral, Madrid, 3 de abril de 1935».

146 Todo este cpígrafe se extrae de ACdV, Asociación Católica de Padres de Familia de Valladolid, «Memoria correspondiente al año 1937».

147 Ibid., pág. 1.

148 «Por encontrarnos en mejores condiciones que otras Asociaciones hermanas, hemos podido procurarlas informes, datos y estadisticas que necesitaban», en Ibid., pág. 3 ,

149 lbid., pág. 3. 


\subsection{La Comisión Depuradora del Magisterio:}

El Presidente de la Asociación es nombrado Vocal de esta Comisión, que durante todo el año de 1937 ha examinado y juzgado miles de informes oficiales y extraoficiales y ha realizado otras gestiones para acabar con todo atisbo de republicanismo o laicismo en la ensenanza: «Labor ingrata, silenciosa, abrumadora, pero necesaria para que en las Escuelas no quede Maestro que pueda pervertir a nuestros hijos, o hacer infértil tanta sangre derramada» $150 . \mathrm{La}$ actividad de la Asociación en este sentido no es nada desdeñable: el Presidente ha contribuído a la depuración de 806 maestros de la provincia y las Oficinas de la Asociación han aportado a la Comisión informes de 229 Maestros de la Capital y Alumnos del Grado Profesional ${ }^{151}$.

Además, la creación de las Comisiones Depuradoras de Bibliotecas y Centros de Lectura contará así mismo con el apoyo de la Asociación, pues la Autoridad Civil dispuso que un representante de las Asociaciones estuviese presente en cada Comisión como Vocal. El trabajo al que se enfrenta, según se señala en la Memoria, es enorme: «os podéis formar una idea pensando en el gran número de Bibliotecas radicantes en este Distrito Universitario, y los innumerables libros que dichas Bibliotecas contienen y que ha de depurar» ${ }^{152}$.

\subsection{Las dificultades para la enseñanza y la represión de la inmoralidad pública:}

La contienda trae importantes trabas a la hora de mantener la enseñanza de los hijos de los asociados, debido a la falta de locales escolares, pues éstos han sido ocupados por las autoridades. Pese a las gestiones realizadas por la Junta Directiva, no fue posible paliar esa falta. La solución que se dispuso fue «dar las clases a unos por la mañana y a otros por la tarde» ${ }^{153}$.

Por otro lado, las gestiones ante el Gobernador Civil para reprimir la inmoralidad dan su fruto, en el sentido de mejorar la clase de impresos de venta en librerías, kioscos y puestos de libros; pese a ello, la represión de todos aquellos libros tenidos como inmorales no se consigue plenamente «por carecer de una Lista o Catálogo Oficial indicador de su moralidad»; por ello, vuelven a ponerse a la venta libros y publicaciones contrarias a esa perseguida moralidad ${ }^{154}$.

\footnotetext{
150 Ibid.

151 Ibid., pág. 2.

152 Ibid., pag, 4.

153 Ibid, pág. 2.

154 Ibid. Las campañas en favor de la moralidad por parte de los Padres de Familia venían siendo aconsejadas por los Metropolitanos en sus Conferencias, desde 1923; ver Cárcel Ortí, V., op. cit., pp. $160,221,254$ y $262-263$.
}

El asociacionismo en la iglesia

Hispania Sacra 50 (1998) 


\subsection{La campaña "Pro Modestia Cristiana ":}

Comienza en el mes de junio por medio de circulares enviadas a los asocia$\operatorname{dos}^{155}$ y carteles en la puerta de casi todas las iglesias de la ciudad ${ }^{156}$. La actividad de propaganda en este sentido fue intensa: con la colaboración de las ramas femeninas de Acción Católica (que repartían octavillas a los transeuntes y pegaban carteles en las fachadas), la Junta Directiva contactó con los párrocos, predicadores, confesores, superiores de Religiosos y Religiosas, y superioras de los Colegios. A todos se les recordó «las disposiciones eclesiásticas sobre la materia, dictas por nuestro Prelado (q.e.p.d.), por los Metropolitanos españoles y por la Sagrada Congregación del Concilio» ${ }^{157}$. También destaca la colaboración del periódico católico Diario Regionall ${ }^{75}$ y la Emisora de radio local Radio Valladolid.

A finales de 1937 no se precisan con exactitud los frutos de la Campaña; sólo se apunta que quizás se deba a la misma el hecho «de que esa moda de traje corto y ceñidísimo, que empezó antes del verano, tuviera entre las clases alta y media mucha menos aceptación que otras anteriores ${ }^{159}$.

\footnotetext{
${ }^{155}$ Así comenzaba la circular:

«Querido amigo y compañero:

Una moda indecente de vestidos ceñidísinos y falda corta amenaza invadir nuestra ciudad. Si ello scría sicmpre censurable, resulta de todo punto intolerable en estos momentos, cuando tantos hijos y hermanos nuestros están sufricndo las penalidades inúmeras (sic) de la guerra, los agudos dolores de las heridas, y tantos otros dieron ya su sangre por liberar a España del materialismo y salvar la civilización cristiana.

Estimándolo así esła Junta ha acordado emprender una campaña contra la deshonestidad en el vestir. (...)», en ACdV, Moralidad Pública, «Circular pasada a todos los asociados-Contra una moda inmoral. Valladolid, 12 de junio de 1937.»

${ }_{156}$ Los pasos que se dieron en la organización de esta campaña fueron: $1^{\circ}$ ) Ponerlo en conocimiento y aprobación del Vicario Capitular $2^{\circ}$ ) Con su aprobación, pedir la cooperación al presidente de la Junta Diocesana de Acción Católica $3^{\circ}$ ) Visitar a los Párrocos para que pongan los respectivos carteles en las Iglesias y que cooperen con esta campaña en el púlpito y en el confesionario $4^{\circ}$ ) Pasar una Circular a los asociados $5^{\circ}$ ) Usar la Prensa y Radio como medio de propaganda $6^{\circ}$ ) Para ejecutar estos acuerdos, se nombró una Comisión formada por los sefiores Lozano, Carro y Ortiz. Ver ACdV, Moralidad Pública, «Campaña contra la inmodestia en el vestir».

157 Ver ACdV, «Memoria...», pág. 2. Se emplean con profusidad textos de Pío XI, del arzobispo Gandásegui y los Metropolitanos sobre este tema, textos de la Sagrada Escritura, etc, todos ellos recogidos en ACdV, Moralidad Pública.

${ }^{158}$ En ACdV, Moralidad Pública, se encuentra una colección de recortes de Diario Regional en apoyo de la Campaña y de la moralidad pública.

$159 \mathrm{ACdV}$, «Mcrnoria...»., pág. 3.
} 


\subsection{En defensa de la moralidad del cine:}

Respecto a este asunto, ya la Confederación elevó importantes escritos al Jefe de Estado y al Gobemador General: el del 26 de enero, que motivó la Orden del 21 de marzo, creando las Juntas de Censura Cinematográfica; y el del 10 de abril, que abogaba por la presencia de un sacerdote en dichas Juntas, en lugar de un representante de las Asociaciones. "Y la Autoridad Civil ha aceptado esta proposición, colocando en nuestro lugar un Representante de la Autoridad Eclesiástica, y no incluyendo en los nuevos Organismos de Censura a los representantes de los Autores y Empresas, por la Orden de 10 de diciembre pasado» ${ }^{60}$.

La Asociación vallisoletana cumple además una serie de medidas elogiadas por la Confederación; la más importante es la que hace referencia al «servicio informativo de cine»: para asegurar la moralidad del mismo, la Asociación coloca los correspondientes Carteles de películas en 33 iglesias, siendo tan elogiada la medida que «la Confederación ha dado instrucciones a las demás asociaciones hermanas para que imiten nuestro servicio informativo de cine» ${ }^{161}$.

\subsection{Los proyectos para el próximo año: la restauración de la cristiandad:}

Las principales actividades proyectadas para el año 1938 poseen un claro carácter reconquistador (en lo católico) y ofensivo frente a cualquier amenaza de signo opuesto a la enseñanza y los valores cristianos ${ }^{162}$ :

1 - Es preciso primero una «paternal y escrupulosa vigilancia» en cualquier ambiente en el que se encuentren los hijos de los asociados: en el hogar, en la escuela, en el cine y demás espectáculos, en los periódicos y libros, en los deportes, en las modas...

2- Colaborar con los Maestros y Profesores en la tarea educativa.

3- $\mathrm{Y}$ por último, un apoyo explícito y reconquistador al nuevo régimen instaurado: «Tenemos, en fin, que cooperar a la restauración de la España imperial y cristiana desempeñando con entusiasmo, fidelidad y celo todos los cargos que nos confien las Autoridades del Nuevo Estado, y también las misiones secundarias que para ello sean precisas»163.

\footnotetext{
160 Ibid.

161 Ibid.

162 Ibid., pág. 4.

163 Ibid.

El asociacionismo en la iglesia

Hispania Sacra 50 (1998)
} 


\section{ANEXOS}

\section{ANEXO I:}

\begin{tabular}{||c|c|c|c|c|}
\hline \hline & $\begin{array}{c}\text { Número de } \\
\text { asociados }\end{array}$ & $\begin{array}{c}\text { Cuota mensual } \\
\text { confederal }\end{array}$ & $\begin{array}{c}\text { Escuelas patrocinadas } \\
\mathrm{y} \mathrm{n} .^{\circ} \text { de niños }\end{array}$ & $\begin{array}{c}\text { Recaudación } \\
\text { mensual }\end{array}$ \\
\hline \hline 1930 & 126 & - & - & - \\
\hline 1931 & 135 & - & - & - \\
\hline 1932 & 243 & $25 \mathrm{pts}$ & - & - \\
\hline 1933 & 368 & $25 \mathrm{pts}$ & $33,3 \mathrm{pts}$ & 24 escuelas \\
\hline 1935 & 803 & 305 niños & 589 \\
\hline 1936 & 973 & $33,3 \mathrm{pts}$ & - & - \\
\hline
\end{tabular}

Fuente: elaboración propia a partir de ACdV, Libro de Actas de la Asociación Católica de Padres de Familia de Valladolid; ibid., Asociación Católica de Padres de Familia de Valladolid. Correspondencia recibida y contestada de la Confederación, en el año de 1932, ibid., de 1934; ACdV, Movimiento de fondos. 1936.

ANEXO II:

\begin{tabular}{||c|c|c|l||}
\hline & INGRESOS & GASTOS & \multicolumn{1}{|c|}{ RESULTADO } \\
\hline 1932 & - & - & Déficit: $1.220 \mathrm{pts}$ \\
\hline 1933 & $6.684,40 \mathrm{pts}$ & $5.804,05 \mathrm{pts}$ & Saldo a favor: $880 ' 35 \mathrm{pts}$ \\
\hline 1934 & $7.540,10 \mathrm{pts}$ & $4.247,60 \mathrm{pts}$ & Saldo a favor: $3.292^{\prime} 50 \mathrm{pts}$ \\
\hline 1935 & $7.685,70 \mathrm{pts}$ & $3.796,05 \mathrm{pts}$ & Saldo a favor: $3.889^{\prime} 65 \mathrm{pts}$ \\
\hline 1936 & $9.340,35 \mathrm{pts}$ & $6.952,45 \mathrm{pts}$ & Saldo a favor: $2.38790 \mathrm{pts}$ \\
\hline
\end{tabular}

Fuentes: Elaboración propia a partir de ACdV, Libro de Actas..., op. cit., pág. 29; ACdV, Asociación Católica de Padres de Familia. Libro Oficial de Contabilidad; ACdV, Movimiento de Fondos. 1936.

El asociacionismo en la iglesia Hispania Sacra 50 (1998) 